\title{
Accessible Statistical Regression, Extrapolation and First-Principles Modelling of Nuclear Data for Spent Nuclear Fuel Composition and Decay Heat Calculations in Short-Term Storage and Recycling
}

\author{
Alistair F. Holdsworth ${ }^{1 *}$, Kathryn George, ${ }^{1}$ Samuel J. S. Adams, ${ }^{1}$ and Clint A. Sharrad ${ }^{1}$
}

1 - Department of Chemical Engineering and Analytical Science, University of Manchester, Oxford Road, Manchester, M13 9PL. *Corresponding Author: Alistair.Holdsworth@manchester.ac.uk

\section{Abstract:}

Computational methods are essential to support and advance nuclear technologies due to the hazards of handling and analysing highly radioactive materials such as spent nuclear fuel (SNF). However, many such methods, including those that can predict SNF compositions and decay heat parameters, require expensive, proprietary software, alongside significant programming experience and computational power for utilisation, severely limiting availability of data and hampering research throughput. Although some datasets are available, many are incomplete or only cover certain fuel systems for older reactor types. Research investigating new methods for SNF recycling, for example, requires compositional and decay heat data for fuel systems not covered by extant data, though analogous source data may be available. With this in mind, we have developed a simple, accessible, and flexible method for extrapolation of isotopic, elemental, and decay heat compositions for SNF at discharge and following decay storage before recycling, based on an extant dataset. This semi-empirical method uses physical and mathematical first principles and can be performed using software accessible to all researchers. This provides outputs accurate to within $1 \%$ of reference values interpolated within the range of available data for isotopic compositions, with sensible extrapolations at higher burnups beyond those reported, with overall elemental outputs accurate to within $0.1 \%$ of expected totals. In this publication, we present the developmental methodology, some sample data, the present limitations, and options for future development and expansion of functionality.

Keywords: Spent Nuclear Fuel; Nuclear Fuel Cycle; Spent Fuel Storage; Spent Fuel Reprocessing; Modelling; Decay Heat; Isotopic Composition; Elemental Composition; Statistical Analysis; First Principles.

\section{1: Introduction}

For research in the development of nuclear technologies across the fuel cycle, computational performance codes and associated methods are essential due to the hazards of radioactive materials. These computational methods not only support the interpretation and understanding of experimental outputs, but also assist to develop appropriate health and safety mitigations and regulatory strategies for hand ling radioactive material applied across laboratory to process scales. However, these codes are often closely-guarded "black-box" systems (e.g. neutron transport and fuel performance codes such as FISPIN, ORIGEN, SERPENT, etc.), ${ }^{1,2}$ requiring extensive programming knowledge, intensive processing power, and proprietary, expensive software for their implementation. ${ }^{1,3,4}$ Similarly, there are very few complete datasets of spent nuclear fuel compositions, ${ }^{2,5}$ though several simplified ${ }^{6-11}$ and some incomplete sets have been published, ${ }^{12,13}$ as part of experimental code validations. ${ }^{14,15}$ This means that such data is often beyond the reach of many researchers, serving to hamper research in the development of advanced nuclear technologies.

With this in mind, and for the purpose of complementing ongoing research into advanced spent nuclear fuel (SNF) recycling technologies, ${ }^{16-20}$ we have developed a simplified model for calculating SNF isotopic, and thus elemental, compositions and the decay heats of unknown spent Gen III(+) Pressurised Water Reactor (PWR) fuels with respect to burnup (BU) and post-reactor cooling times up to a decade. This is achieved by interpolating within and extrapolating beyond the known burnup data range on an isotopic level, ${ }^{21}$ and serves to address the lack of specific data required. This complements our own research in the published literature, as there is worldwide interest in developing SNF recycling technologies to support future fuel cycles where reactors are likely to operate at higher burnups than has previously been the case (i.e. $>60$ $\mathrm{GWd} / \mathrm{tHM}$ ) which is beyond the range of extant data. Our approach utilises software commercially available to the vast majority of researchers in conjunction with accessible source data ${ }^{5}$ using methods that require a minimum of specialist knowledge beyond scientific first principles and basic statistical analysis techniques.

We discuss the rationale behind the modelling approach and present our methodology alongside some sample data, with further assessment of the limitations of the model and potential further work to be undertaken. Although similar analyses have been utilised on nuclear data recently, these relied on more intensive approaches, ${ }^{3}$ or investigated different factors of fuel behaviour. ${ }^{4}$ To our knowledge, this represents the first instance of this approach being applied to nuclear data and could be adapted to other complex datasets in a range of academic fields, alongside applications in the wider nuclear fuel cycle. This information will be utilised to discern the effects of separations on downstream processes, conversion, and storage in SNF recycling, ${ }^{16-20}$ expanding beyond the available source data ${ }^{5}$ and extrapolating to cover Gen III+ reactor systems. We believe this could contribute to improvements on the design of new SNF recycle and waste management facilities, ${ }^{22}$ to facilitate wider, cost-effective management of the vast quantities of SNF stored worldwide and that produced by advanced Gen III(+) reactors, such as the EPR, which are coming online at the time of writing. ${ }^{2}$ 


\section{2: Methodology}

\section{1: Software and Data Sources}

All analyses and calculations were conducted in Microsoft Office Excel (Build 12.0.6787.5000 SP3). Isotopic compositional information, calculated using the ORIGEN2 fuel performance code for $5 \%$ enriched, $60 \mathrm{GWd} / \mathrm{tHM} \mathrm{UO}{ }_{2}$ PWR fuel presented in Ref. 5 was used to derive extrapolation parameters, for error checking purposes, and for the zero-burnup fuel composition. The ORIGEN2 fuel performance code has been experimentally validated for PWR fuel systems and can be considered to provide accurate predictions of SNF compositions. ${ }^{14,15}$ All actinide and fission product isotopes where nuclide concentrations are greater than $1.0000 \mathrm{~g} / \mathrm{tHM}$ at discharge were utilised. The concentration values and their variation with burnup (0-60 GWd/tHM range) presented in the source data are given to five significant figures and were used as recorded. This process served to omit the majority of transient, short-lived nuclides and actinide decay products, providing a total heavy metals (HM) composition constituting $\geq 99.9 \%$ by mass of the presented data. ${ }^{5}$ Note that while data for the oxide counterions and associated activation products are available in the source, ${ }^{5}$ these are not required for the scope of this work. Where quoted, neutron capture and fission cross sections are expressed for thermal neutrons in barns (b), and all isotope concentrations are given as g/thM (grams per ton of heavy metal). Information regarding isotopic fission yields, isotopic neutron capture/fission cross-sections, decay energies, and half-lives were acquired from the IAEA Nuclear Isotope Browser (IAEA Nuclear Data Section, App Code 117, Name 5.13.73) or the IAEA Live Chart of Nuclides. $^{23}$

\section{2: Regression Analysis}

Polynomial, log-log, and log-lin approaches were explored for each of the nuclides to find the best fit to the available for the variation of the concentration of each isotope with burnup. This provides confidence when extrapolating to fuel conditions and burnups where compositions are not established or available. The relative error between calculated and reference composition data for each nuclide was used to provide a quantifiable comparison between these approaches, calculated as per Equation $\mathbf{1}$ where [Nuc] is the nuclide concentration at each burnup (BU) point, calc is the calculated value, and ref is the literature reference value. ${ }^{5}$ Similar calculations are used to determine the accuracy of fuel performance codes relative to experimental data. ${ }^{12,14}$

$$
\% \text { Error }=\left([\mathrm{Nuc}]_{\text {Calc }}-[\mathrm{Nuc}]_{\text {Ref }}\right) /[\mathrm{Nuc}]_{\text {Ref }} \times 100
$$

\subsection{1: Polynomial Regression}

Polynomial regressions were calculated by plotting [Nuc] against BU (where [Nuc] is the $y$ variable, and $B U$ the $x$ variable) for each isotope as $x$ y scatter plots. The Excel polynomial trendline function was utilised for quadratic, cubic, and quartic functions, ${ }^{24}$ according to Equation 2 , with intercepts forced to 0 for the vast majority of fission product (FP) and some actinide isotopes unless otherwise stated, while for the $U$ isotopes, the initial starting concentrations from the source data ${ }^{5}$ were utilised. As the Excel trendline function is limited to 4 decimal points (for small values) or 5 significant figures (for large values), nuclides with low [Nuc] values had their concentration values multiplied by $10^{3}$ for this purpose, as this increases accuracy particularly for the $a$ and $b$ terms (Equation 2) which are very sensitive to small multiplication factors. For example, an $a$ value rounded to 0.0002 may in fact be 0.0002498 , which would appear as 0.2498 with this multiplication applied. Parameters derived in this manner were divided by $10^{3}$ before incorporation into the model. The concentration variations for some of the heavier minor actinide (MA) isotopes (Am and Cm primarily) were only fitted for burnups above 10, 20, or $30 \mathrm{GWd} / \mathrm{tHM}$ dependent on the isotope due to low concentrations below these values, as noted in the discussion below. This improved the accuracy of the curve fits and is explained in the main text below.

$$
y=a x^{4}+b x^{3}+c x^{2}+d x+e
$$

\subsection{2: Logarithmic Regression}

Log-log and log-lin regressions were conducted by taking base 10 log values of both radionuclide concentrations and burnup values. Both log$\log$, and $\log ([\mathrm{Nuc}])-\operatorname{lin}(\mathrm{BU})$ were plotted as $\mathrm{x}$-y scatter plots for each isotope along with linear trendlines, where $\mathrm{y}$ and $\mathrm{x}$ are the [Nuc] and $\mathrm{BU}$ functions respectively. Gradient, intercept, and $R^{2}$ values for these trendlines were determined, corresponding to Equations 3 to 6 and the derived outputs for the log-log, and log-lin plots respectively. These parameters were then fed back into the respective equations to provide extrapolated concentrations and the errors calculated as described above utilising the approach (log-log or log-lin) with the highest $R^{2}$ value.

$$
\begin{aligned}
& \log y=k \cdot \log x+\log a \\
& y=10^{k} \cdot x^{a} \\
& \log y=m x+\log k \\
& y=m \cdot x^{k}
\end{aligned}
$$

\section{3: Decay Modelling and Decay Heat Calculations}

Radioactive decays were modelled using the decay equation (Equation 7), with exponential decay constants $\left(\lambda\right.$, in $\left.y^{-1}\right)$ calculated as per Equation 8, where $\mathrm{N}_{0}$ and $\mathrm{N}_{\mathrm{t}}$ are the radionuclide concentrations at discharge and at time $\mathrm{t}$ (in years), and $\mathrm{t}_{0.5}$ is the isotope half life (years). 


$$
\begin{aligned}
& N_{t}=N_{0} \cdot e^{-\lambda / t} \\
& \lambda=\ln 2 / t_{0.5}
\end{aligned}
$$

Gravimetric decay heats $\left(E_{d}, W / g\right)$ were calculated on a per-nuclide basis to function as seamlessly as possible with the concentration values utilised elsewhere in this model using Equation 9, where $Q_{a / b}$ is the total alpha or beta decay energy (including gamma, J), $A_{i}$ is the isotopic mass $(\mathrm{g} / \mathrm{mol}), \mathrm{N}_{\mathrm{A}}$ is Avogadro's constant $\left(6.022 \times 10^{23} \mathrm{~mol}^{-1}\right)$, and $\mathrm{t}_{0.5}$ is the half-life (in seconds for this purpose).

$$
E_{d}=\left(Q_{a} / b / A_{i} \cdot N_{A}\right) \cdot\left(\operatorname{Ln} 2 / t_{0.5}\right)
$$

\section{3: Results and Discussion}

\section{1: Method Development}

A summary of the mathematical and statistical operations utilised in the development of our model is presented in the Figure $\mathbf{1}$ flowchart for context, highlighting the various manual and data inputs, calculation processes and internal databases. These are discussed subsequently to explain the logical progression of our model from the source data (Sections 3.1 to 3.5) to the example outputs presented in Section 3.6.

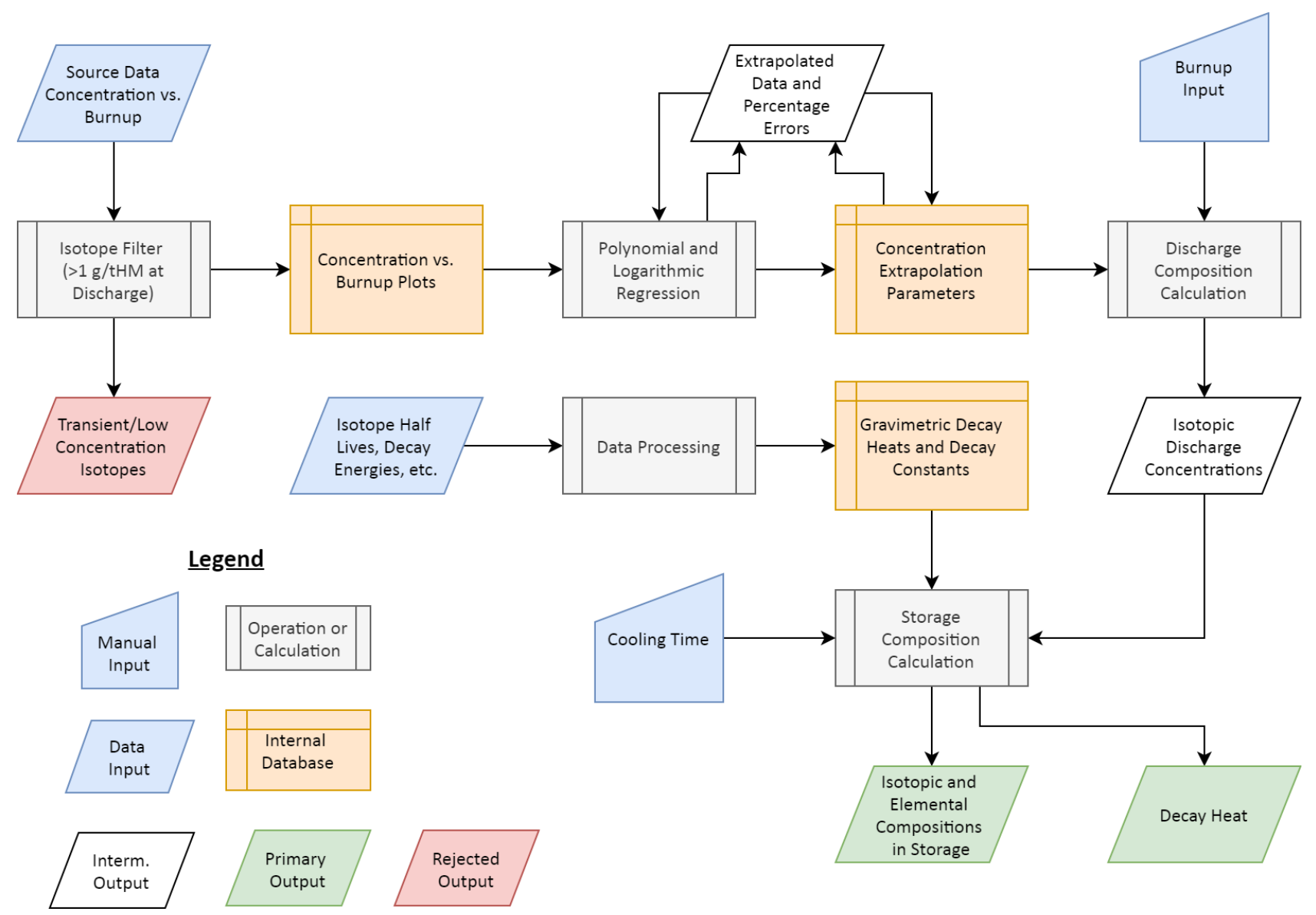

Figure 1: Flowchart of operations presented in this publication highlighting both manual and data inputs (blue), outputs (rejected in red, transient in white, and targets/primaries in green), operations (grey), and internal storage (orange).

The relevant data for our model were identified using source isotope concentrations for $60 \mathrm{GWd} / \mathrm{tHM}$ discharge burnup, $5 \%$ initial enrichment PWR $\mathrm{UO}_{2}$ fuel, ${ }^{5}$ with a starting $\mathrm{HM}$ composition containing ${ }^{234} \mathrm{U},{ }^{235} \mathrm{U},{ }^{236} \mathrm{U}$, and ${ }^{238} \mathrm{U}$. The concentration vs. burnup data for all isotopes with discharge concentrations at $60 \mathrm{GWd} / \mathrm{tHM}$ of $1.0000 \mathrm{~g} / \mathrm{tHM}$ or higher were extracted from the source and tabulated. This encompassed the light and heavy fission products (FPs) and the actinides, as outlined in Table 1, while serving to omit the vast majority of transient or lowconcentration nuclides which are of little significance in SNF recycling and serves to simplify our model. These could be incorporated if the end user required, as discussed later. This provides the concentration vs. burnup plots that would be used as the basis for regression analysis, which provide the parameters for interpolation and extrapolation operations.

The polynomial and two logarithmic regressions were then performed on each burnup-concentration plot separately for each isotope within the $0-60 \mathrm{GWd} / \mathrm{tHM}$ range presented in the source data. ${ }^{5}$ The best-fit polynomial parameters (quadratic, cubic, or quartic) for each isotope (Equation 2), and those for the log-log (Equation 3) and log-lin (Equation 5) regressions were recorded alongside determination coefficients $\left(R^{2}\right.$ values). The zero-burnup concentration values for the $U$ isotopes were forced as intercepts for the polynomial regressions, while enforcing zero intercepts for the majority of FPs and transuranic actinides improved the accuracy of the curve fits at low burnups. Concentration values 
for each isotope at each burnup level were then calculated utilising these derived parameters and the percentage error (Equation 1) for each method calculated across the burnup range of the source data. An example for the $U$ isotopes is presented in Table $\mathbf{2}$, including the various equation parameters and regression coefficients.

Table 1: Fission product and actinide isotope inputs for our model, grouped by element. The threshold for inclusion was a minimum concentration of $1.0000 \mathrm{~g} / \mathrm{tHM}$ at $60 \mathrm{GWd} / \mathrm{tHM}$ discharge. Concentration vs. BU values were recorded for each isotope from the source. ${ }^{5}$

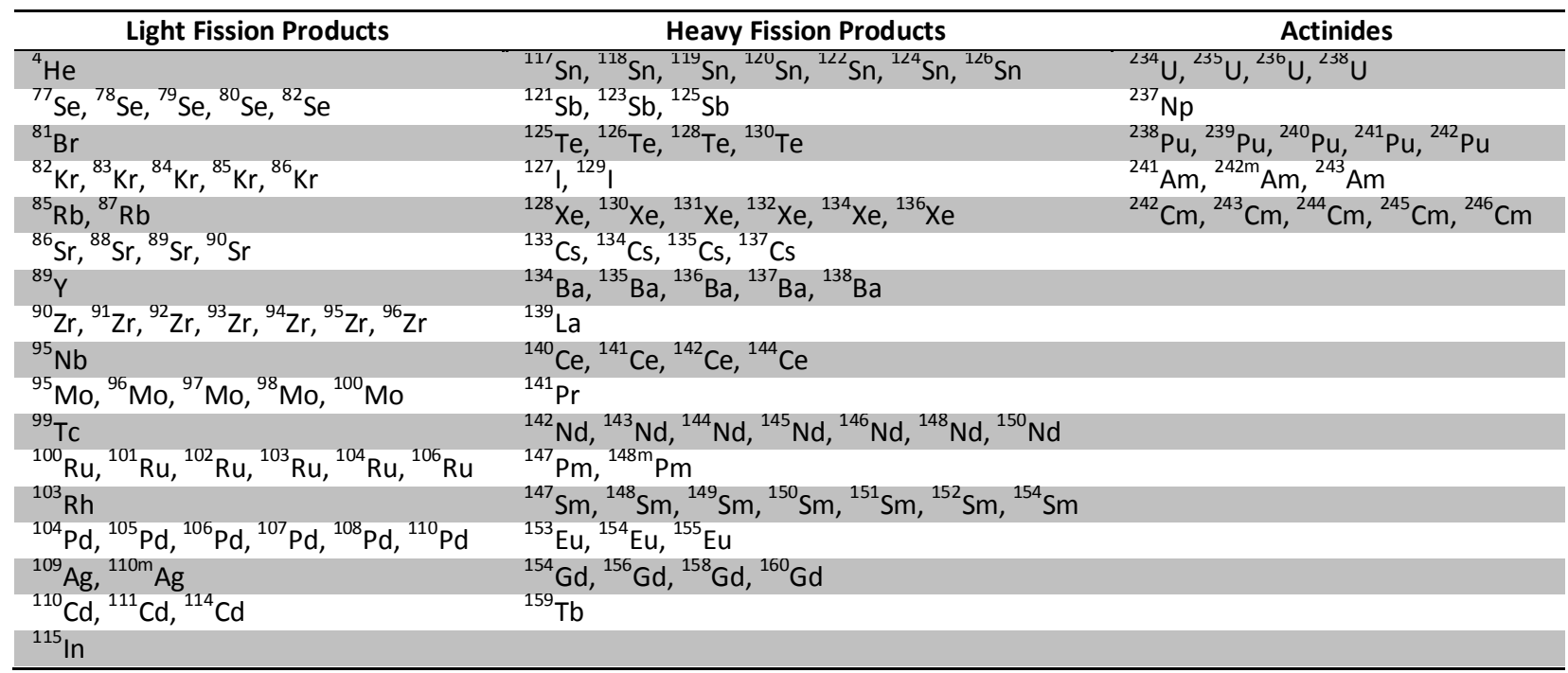

It can be clearly seen that the polynomial (quadratic) regression provides the closest fit to the experimental data, followed by the log-lin approach (for all $\mathrm{U}$ isotopes except ${ }^{236} \mathrm{U}$ ) and finally $\log$ - $\log \left(\right.$ for ${ }^{236} \mathrm{U}$ ). This is a recurring observation throughout all of the isotopes tested, with some minor deviations discussed later for several steady-state, shorter-lived, or high-capture FP nuclides.

Table 2: $U$ isotope regression analysis for quadratic, log-lin, and log-log methods.

\begin{tabular}{lllllllllll}
\hline Isotope & \multicolumn{4}{c}{ Polynomial } & \multicolumn{3}{c}{ Log-Lin } & \multicolumn{3}{c}{ Log-Log } \\
\hline${ }^{234} \mathrm{U}$ & $\mathrm{c}$ & $\mathrm{d}$ & $\mathrm{e}$ & $\mathrm{R}^{2}$ & $\mathrm{~m}$ & $\operatorname{logk}$ & $\mathrm{R}^{2}$ & $\mathrm{a}$ & $\operatorname{logk}$ & $\mathrm{R}^{2}$ \\
${ }^{235} \mathrm{U}$ & 0.0144 & -5.0833 & 461.1 & 1.0000 & -0.0058 & 2.6722 & 0.9972 & -0.3692 & 3.0178 & 0.9146 \\
${ }^{236} \mathrm{U}$ & -1.1292 & -1113.0 & 50000 & 0.9998 & -0.0126 & 4.7220 & 0.9954 & -0.811 & 5.4811 & 0.9053 \\
${ }^{238} \mathrm{U}$ & -1.6451 & 204.91 & 308.2 & 0.9996 & 0.0182 & 2.9553 & 0.6850 & 0.6187 & 2.7581 & 0.9845 \\
\hline
\end{tabular}

Other accommodations in order to achieve the best fit are noted in the discussions for the fission products and minor actinides presented below. The percentage errors recorded for each concentration curve calculated for the different regression methods presented in Table $\mathbf{2}$ are plotted graphically in Figure 2.

We observe similar trends in percentage errors for the uranium isotopes presented in Figure 2, with the exception of ${ }^{236} \mathrm{U}$. Of the regression methods tested, the polynomial (quadratic in this case) fit shows by far the smallest deviation from the source data relative to the two logarithmic methods. With this in mind, we focused on the polynomial method for the subsequent analyses, as this provided far lower deviation from the experimental data for the bulk of the nuclides modelled alongside more flexible modelling and overall better fits for the vast majority of isotopes in our model. The process of utilising the extrapolated data and percentage errors to derive suitable extrapolation parameters is discussed separately for the FPs and actinides below.

\section{2: Modelling the Variation in Fission Product Discharge Concentrations with Burnup}

While the yields of fission products in the absence of any other factors would be linear, in practice this is not the case due to neutron capture reactions. Those isotopes of fission products analysed in our model can be divided into several categories depending upon their behaviour and route of formation during reactor irradiation of fuel:

- $\quad$ Those produced directly by fission but depleted by neutron capture and transmutation, e.g. ${ }^{131}$ Xe, Figure 2.

- Those produced by fission and also augmented by neutron capture and/or transmutation from lighter isotopes, e.g. ${ }^{132}$ Xe, Figure 2 .

- "Steady-state" fission product nuclides which are relatively short-lived or rapidly transmuted, e.g. ${ }^{141} \mathrm{Ce}$, Figure 3.

- "Shielded" nuclides produced via neutron capture, e.g. ${ }^{134} \mathrm{Cs}$, Figure 4, which cannot be produced via decay processes. ${ }^{14}$ 

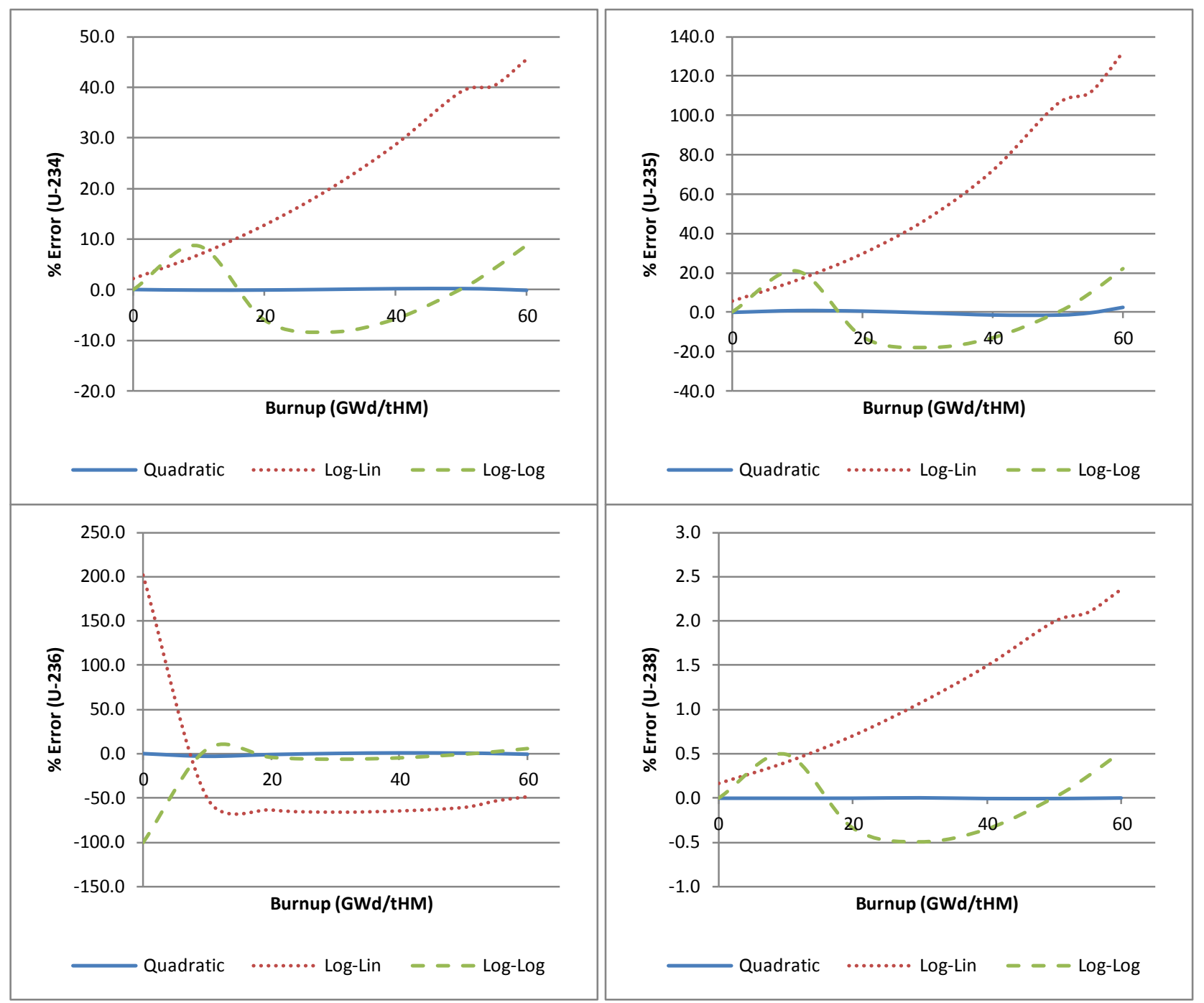

Figure 2: Variation in percentage errors between polynomial (quadratic), log-lin, and log-log-derived regression parameters for ${ }^{234} \mathrm{U}$ (top left), ${ }^{235} \mathrm{U}$ (top right), ${ }^{236} \mathrm{U}$ (bottom left), and ${ }^{238} \mathrm{U}$ (bottom right).

These are not exclusive, however, and combinations of these processes can occur, especially where short-lived high-capture poisons (such as ${ }^{135} \mathrm{Xe}$ ) are involved. Given our source data and the intended output targets from our model, however, such intricacies are beyond the scope of the processes presented here. Figures 3-5 also serve to illustrate several necessary accommodations and limitations in our model, discussed with each figure.

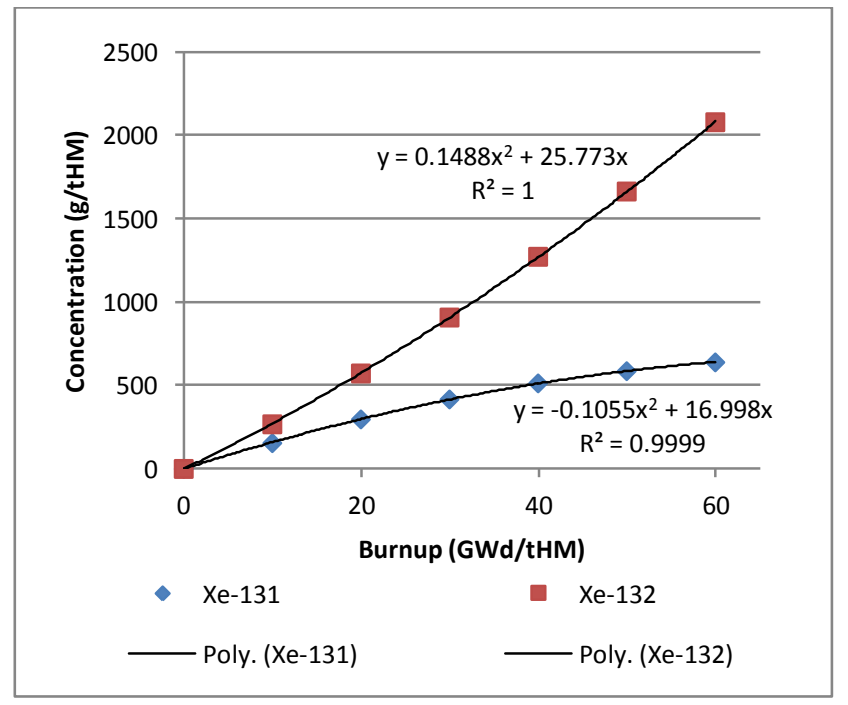

Figure 3: Variation in ${ }^{131} \mathrm{Xe}$ and ${ }^{132} \mathrm{Xe}$ concentrations with burnup. 
Figure 3 illustrates two stable nuclides, ${ }^{131} \mathrm{Xe}$ and ${ }^{132} \mathrm{Xe}$, produced as direct fission products during irradiation with opposing concentration effects due to neutron capture. The direct ${ }^{235} \mathrm{U}$ yields of these two isotopes are $2.88 \%$ and $4.30 \%$ of thermal fissions with masses 131 and 132 , respectively. The difference in concentration arises due to the high neutron-capture cross section of ${ }^{131} \mathrm{Xe}(93 \mathrm{~b})$, compared to that of ${ }^{132} \mathrm{Xe}$ $(0.45 \mathrm{~b})$, resulting in conversion via the $(n, \gamma)$ reaction. This is a common process observed for many of the FP isotopes in our model. Decay processes are less significant for the build-up of stable or longer-lived isotopes such as these in nuclear fuel during irradiation, rather than neutronic effects which result in transmutations at the expense of reactor neutron efficiency.

Indeed, it is the build-up of neutron poisoning fission products in fuel alongside the depletion of fissile isotopes that necessitate refuelling operations, and ideally SNF recycling in a fully-closed fuel cycle. With respect to modelling these types of isotopes, curve fitting with quadratic regression and a forced zero intercept provides adequate modelling of concentrations, though for isotopes such as ${ }^{131}$ Xe, a maximum will eventually be reached beyond which concentrations will decline, rather than the steady state observed in reality.

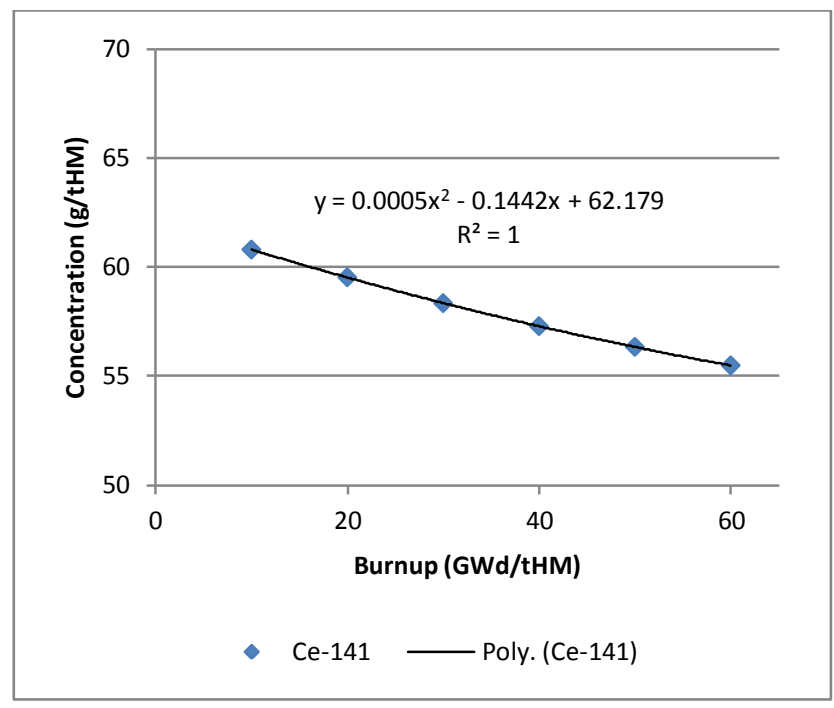

Figure 4: Variation in ${ }^{141}$ Ce concentration with burnup.

Shorter-lived fission product nuclides, and those which are rapidly transmuted will reach a steady-state within an operational reactor, as illustrated by ${ }^{141} \mathrm{Ce}$ in Figure 4 . This isotope has a half-life of $32.5 \mathrm{~d}$, a thermal neutron capture cross-section of $29 \mathrm{~b}$, and is produced in $5.86 \%$ of thermal ${ }^{235} \mathrm{U}$ fissions. It is an intermediate in the mass 141 decay chain, forming the stable ${ }^{141} \operatorname{Pr}$ by $\beta^{-}$decay. In order to simplify the curve fitting for isotopes such as ${ }^{141} \mathrm{Ce}$, the 0 -burnup 0 -concentration point was omitted and the $y$-axis intercept was not forced. Although such isotopes tend to be short-lived, they are often significant contributors to short-term (up to 1 y) post-discharge decay heat, and as such are included in the model for this purpose.

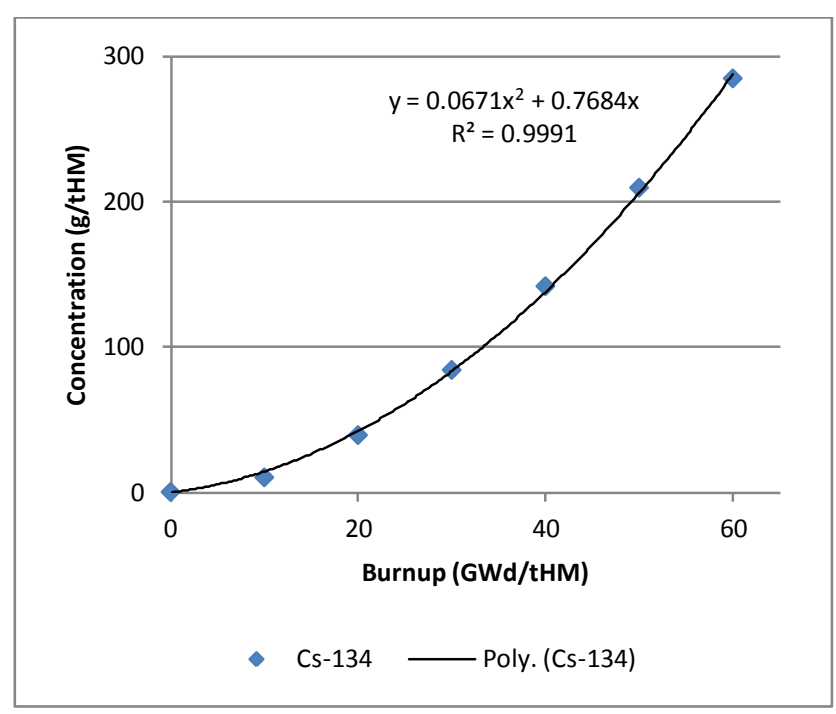

Figure 5: Variation in ${ }^{134} \mathrm{Cs}$ concentration with burnup.

A range of nuclides not accessible directly via fission processes due to being "shielded" by stable or long-lived lower-Z elements of the same isotones are produced via neutron capture reactions from lighter FP isotopes during nuclear fuel irradiation. ${ }^{14}$ Examples of this include the radioactive ${ }^{134} \mathrm{Cs}$ isotope, produced by neutron capture from stable ${ }^{133} \mathrm{Cs}$ but shielded from direct production by ${ }^{134} \mathrm{Xe}$, and the stable ${ }^{96} \mathrm{Mo}$, 
produced from stable ${ }^{95}$ Mo. Figure 5 presents an example where the quadratic regression provides an acceptable fit to the source data $\left(R^{2}=\right.$ $0.9991)$, but a more accurate fit can be gained by the addition of a cubic term $\left(R^{2}=1\right)$.

For the purposes of our model, we are concerned with interpolation within the range of data available and extrapolation beyond the maximum reported $60 \mathrm{GWd} / \mathrm{tHM}$. With this in mind, the behaviour of all modelled isotopes (both FPs and actinides) was extrapolated using the optimised regression parameters between simulated 0 and $100 \mathrm{GWd}$ /tHM burnups, with any FP isotopes displaying concentration maxima or other phenomena within this region recorded, as outlined in Table 3. We recognise that, due the nature of our model, some isotopes are likely to present erroneous behaviour at elevated burn ups, which could be corrected with more complex approaches to modelling their concentrations, perhaps with combinations of polynomial and logarithmic functions of burnup. Though these values presented go beyond the intended operational range of our model, designed to model burnups $20 \%$ increased over the source data ${ }^{5}$ to $75 \mathrm{GWd} / \mathrm{tHM}^{\mathrm{m}}$, this serves to highlight current limitations.

Table 3: FP Isotopes displaying concentration maxima.

\begin{tabular}{ccc}
\hline Isotope & Model & Burnup at Maximum (GWd/tHM) \\
\hline${ }^{83} \mathrm{Kr}$ & Quad. & $75-80$ \\
${ }^{85} \mathrm{Kr}$ & Quad. & 95 \\
${ }^{90} \mathrm{Sr}$ & Quad. & 100 \\
${ }^{95} \mathrm{Mo}$ & Cubic & 75 \\
${ }^{109} \mathrm{Ag}$ & Cubic & $95-100$ \\
${ }^{131} \mathrm{Xe}$ & Cubic & 80 \\
${ }^{144} \mathrm{Ce}$ & Quart. & 50 \\
${ }^{143} \mathrm{Nd}$ & Cubic & $75-80$ \\
${ }^{147} \mathrm{Pm}$ & Quad. & 45 \\
${ }^{148 m} \mathrm{Pm}$ & Quad. & 45 \\
${ }^{153} \mathrm{Eu}$ & Cubic & 65 \\
${ }^{154} \mathrm{Eu}$ & Cubic & 95 \\
\hline
\end{tabular}

\section{3: Modelling the Variation in Actinide Discharge Concentrations with Burnup}

In many respects, the behaviour of the actinides, especially the transuranics during reactor irradiation, is more complex than that of the fission products, and thus modelling their behaviour using this method is more challenging. This is due to the complex series of competing creation, fission, conversion, and decay reactions all affecting the concentrations of these nuclides simultaneously. As such, the relevant actinides and their isotopes will be discussed in greater detail on an element-by-element basis, with the derived parameters presented at the end of this section in Table 4.
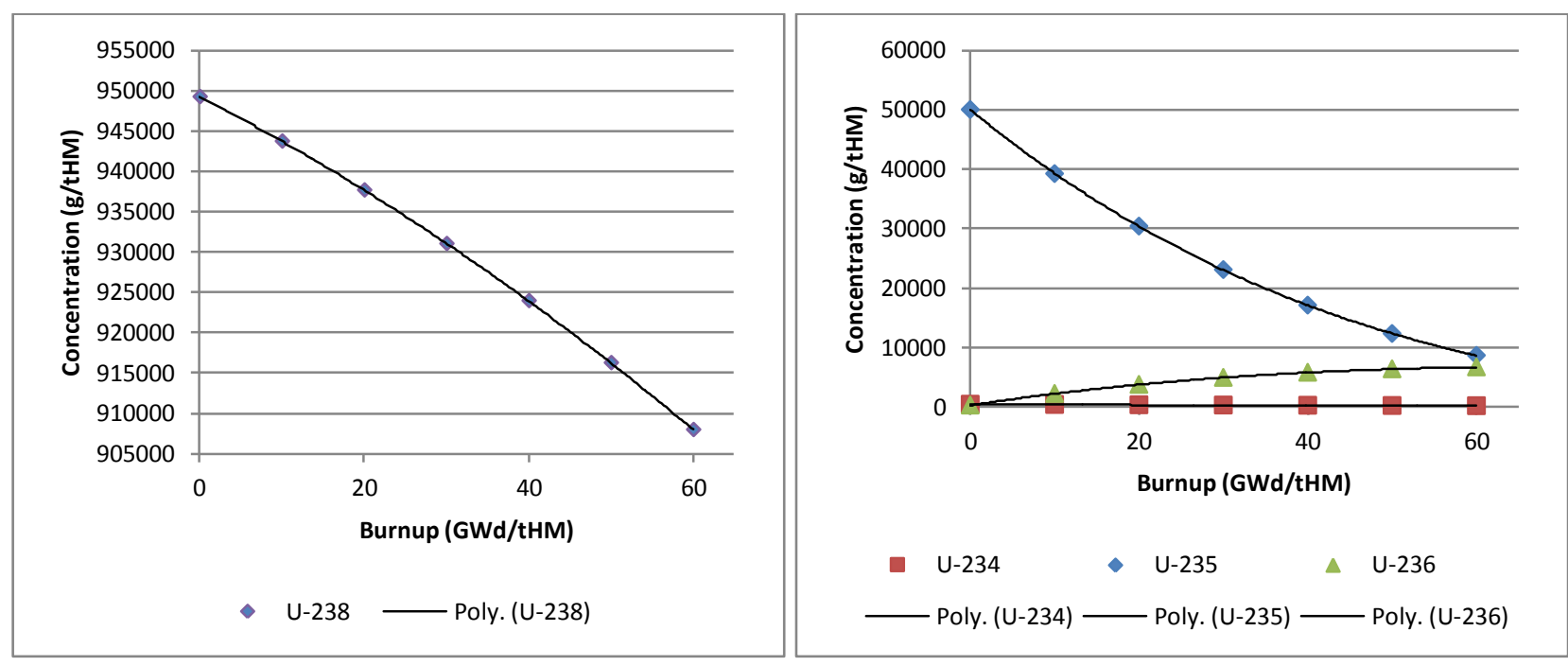

Figure 6: Experimental variations in concentration with burnup and polynomial fits for ${ }^{234} \mathrm{U},{ }^{235} \mathrm{U},{ }^{236} \mathrm{U}$, and ${ }^{238} \mathrm{U}$.

\subsection{1: Uranium}

We have already presented the conversion of uranium isotopes as an example of the different possible regression analyses above. Of all the actinides, the conversion of uranium isotopes between each other by neutron capture, decay, and fission is the simplest to model and accurate fits with the experimental data are readily achieved using polynomial models. The interpretation of ${ }^{234} \mathrm{U},{ }^{235} \mathrm{U}$, ${ }^{236} \mathrm{U}$, and ${ }^{238} \mathrm{U}$ using this method is presented in Figure 6. This encompasses nuclear processes which facilitate the conversion of ${ }^{234} \mathrm{U}$ to ${ }^{235} \mathrm{U}$ by neutron capture (102.5 b), the fission of ${ }^{235} \mathrm{U}(582.6 \mathrm{~b})$ and neutron capture to ${ }^{236} \mathrm{U}(98.8 \mathrm{~b})$, the neutron capture of ${ }^{236} \mathrm{U}$ to the short-lived ${ }^{237} \mathrm{U}\left(5.09 \mathrm{~b}, \mathrm{t}_{0.5}=6.752 \mathrm{~d}\right)$ and 
conversion to ${ }^{237} \mathrm{~Np}$, and the breeding of ${ }^{238} \mathrm{U}$ to ${ }^{239} \mathrm{Pu}$ by neutron capture (2.682 b), via the short-lived intermediates ${ }^{239} \mathrm{U}$ and ${ }^{239} \mathrm{~Np}\left(\mathrm{t}_{0.5}=23.5\right.$ min and $2.36 \mathrm{~d}$, respectively).

As uranium represents the bulk content of SNF, its concentrations and isotopic content are essential information when considering recycling processes, though the decay of its isotopes can largely be ignored for the purposes of this work due to the long half-lives of the majority of nuclides present. Quadratic fits were used for ${ }^{234} \mathrm{U}$ and ${ }^{238} \mathrm{U}$ and cubic fits for ${ }^{235} \mathrm{U}$ and ${ }^{236} \mathrm{U}$, with the $\mathrm{y}$-intercepts forced to the starting concentration for each isotope, providing $\mathrm{R}^{2}=1$ in all cases. These fits function well up to $75 \mathrm{GWd} / \mathrm{tHM}$. Beyond $95 \mathrm{GWd} / \mathrm{tHM}$, however, the ${ }^{235} \mathrm{U}$ concentration is predicted to be negative, and would require additional source data to accurately model.

\subsection{2: Neptunium}

The only neptunium isotope of significance for the purposes of this work is ${ }^{237} \mathrm{~Np}$, produced by neutron capture followed by $\beta^{-}$decay from ${ }^{236} \mathrm{U}$. The heavier isotopes are all transients in the conversion to other nuclides, while the lighter ones are of little significance generally due to their low concentrations and short half-lives. ${ }^{237} \mathrm{~Np}$ serves as one of the precursors to the relatively short-lived and high-decay heat emitting ${ }^{238} \mathrm{Pu}$ isotope by neutron capture followed by beta decay. Np is problematic in SNF recycling due to its partitioning in solvent extraction processes, and is environmentally mobile as the neptunyl ion $\left(\mathrm{NpO}_{2}{ }^{+}\right)$in storage scenarios. ${ }^{237} \mathrm{~Np}$ is produced via 2 routes - in reactor conditions via neutron capture by ${ }^{236} \mathrm{U}$ followed by beta decay, and by the alpha decay of ${ }^{241} \mathrm{Am}$ that is primarily encountered during the storage of SNF.

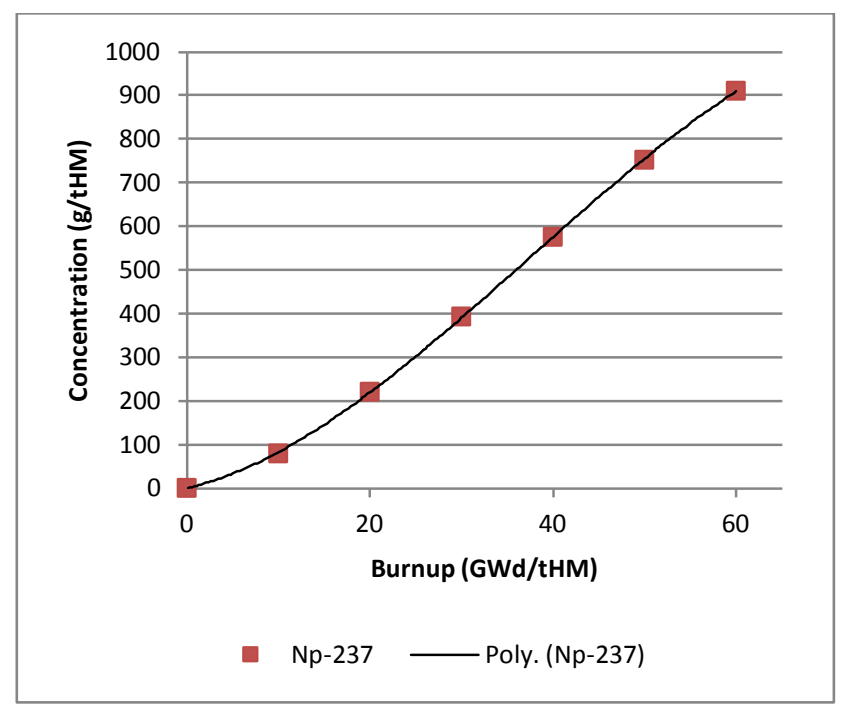

Figure 7: Experimental variation in concentration with burnup and polynomial fit for ${ }^{237} \mathrm{~Np}$.

The variation in Np concentration with burnup from the source data and our model fit is presented in Figure 7. A cubic fit was used for the ${ }^{237} \mathrm{~Np}$ model with a y-intercept of zero forced for low-burnup accuracy of the fit. The initial upwards trend in concentration up to $30 \mathrm{GWd} / \mathrm{tHM}$ decreases at burnups above $50 \mathrm{GWd} / \mathrm{tHM}$, necessitating the cubic model. This does mean that a maximum in Np concentration is encountered at around $83 \mathrm{GWd} / \mathrm{tHM}$ when extrapolating beyond the range of the source data. Beyond $83 \mathrm{GWd} / \mathrm{tHM}$, a rapid decrease in Np concentration with respect to burnup is predicted by the cubic model, and is considered to be unlikely under actual reactor conditions. SNF compositions outside the bounds of the source data used in this work are therefore required in order to provide confidence in the validation of these models.

\subsection{3: Plutonium}

Five Pu isotopes (masses 238 to 242) are of significance due to the inherent concentrations of these isotopes in SNF combined with concerns on criticality safety and proliferation, ${ }^{14,25}$ and accurate predictions of concentrations are essential in recycling and storage scenarios. The longlived ${ }^{244} \mathrm{Pu}$ is not produced in appreciable quantities (due to the short-lived ${ }^{243} \mathrm{Pu}$ precursor) to be of concern. Of these isotopes, ${ }^{239} \mathrm{Pu}$ and ${ }^{241} \mathrm{Pu}$ are fissile, although the latter of these decays with a half-life of 14.1 years to ${ }^{241} \mathrm{Am}$, reducing the fissile content of SF over time while increasing the decay heat load from decay of ${ }^{241} \mathrm{Am}$, as discussed later. ${ }^{239} \mathrm{Pu}$ concentrations stabilise above a burnup of $\sim 40 \mathrm{GWd} / \mathrm{tHM}$ due to the rate of fission and conversion to heavier isotopes reaching equilibrium with the rate of production. Similar effects are observed for ${ }^{240} \mathrm{Pu}$ and ${ }^{241} \mathrm{Pu}$, although the equilibrium concentrations are reached at higher burnups. ${ }^{242} \mathrm{Pu}$ concentrations increase significantly at higher burnups, while production is relatively low below $30 \mathrm{GWd} / \mathrm{tHM} .{ }^{238} \mathrm{Pu}$ is produced primarily via neutron capture from ${ }^{237} \mathrm{~Np}$, though the decay of the short-lived ${ }^{242} \mathrm{Cm}$ also provides some of this isotope. The variation in Pu isotope concentrations with burnup and our fits to the data are presented in Figure 8. In some circumstances, isotopic ratios within an element are highly useful in fields such as nuclear forensics, and can be readily extracted from the outputs of our model. ${ }^{5,14}$

${ }^{238} \mathrm{Pu}$ and ${ }^{242} \mathrm{Pu}$ are the simplest isotopes to model due to their concentration trends in SNF with burnup, and are well fitted with quadratic functions with forced zero intercepts. ${ }^{240} \mathrm{Pu}$ and ${ }^{241} \mathrm{Pu}$ were modelled with cubic functions, with the zero-burnup data point omitted and no $\mathrm{y}$ - 
axis intercept forced. While this reduces model accuracy at low burnups, the accuracy of this model improves at the higher BU values of interest in this work. ${ }^{239} \mathrm{Pu}$ requires a quadratic function for an acceptable fit, with the same accommodations as for ${ }^{240} \mathrm{Pu}$ and ${ }^{241} \mathrm{Pu}$. The complexity of variation within the $\mathrm{Pu}$ isotopes relative to many of the others modelled may require the use of more advanced functions, such as a combination of exponential and polynomial functions for more comprehensive modelling of their behaviour, though in a first instance, these provide reasonable extrapolations up to $70 \mathrm{GWd} / \mathrm{tHM}$ burnups. Concentration maxima as observed for ${ }^{237} \mathrm{~Np}$ are recorded for ${ }^{240} \mathrm{Pu}$ and ${ }^{241} \mathrm{Pu}$ around $80 \mathrm{GWd} / \mathrm{tHM}$ burnup, and the predicted concentrations of ${ }^{239} \mathrm{Pu}$ increase beyond $70 \mathrm{GWd} / \mathrm{tHM}$.

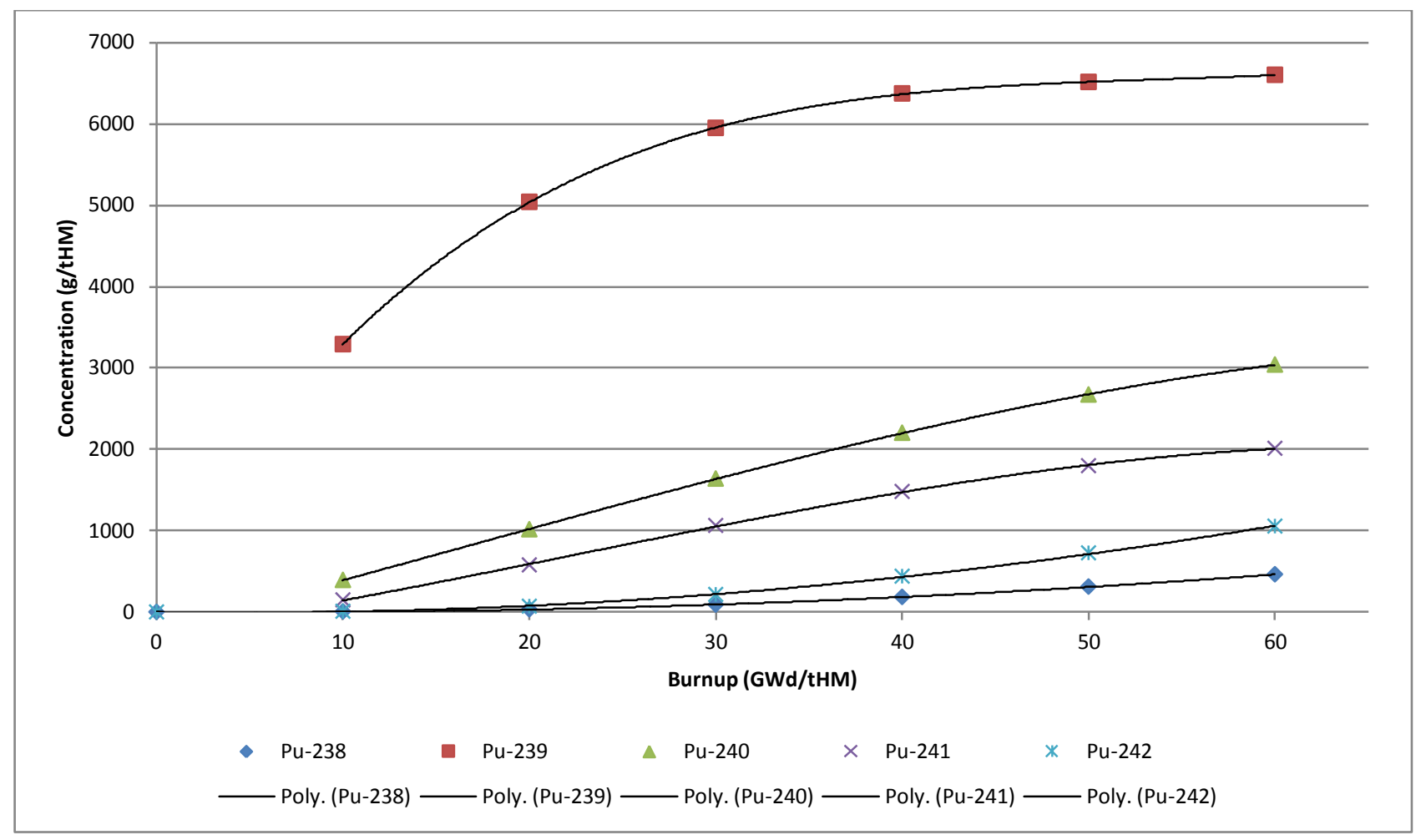

Figure 8: Experimental variations in concentration with burnup and polynomial fits for ${ }^{238} \mathrm{Pu}$ to ${ }^{242} \mathrm{Pu}$.

\subsection{4: Americium}

The isotopes of americium present a significant source of long-term radiotoxicity in SNF as medium-lived $\alpha$-emitters, especially due to the production of ${ }^{241} \mathrm{Am}$ from the decay of ${ }^{241} \mathrm{Pu}$, which continues for decades in SNF storage scenarios and in the storage of MOX fuel. This isotope, with a half life of 432 years, thus accumulates in even purified Pu samples over time. The longer-lived ${ }^{243} \mathrm{Am}\left(\mathrm{t}_{0.5}=7364 \mathrm{y}\right)$ is produced via neutron capture from ${ }^{242} \mathrm{Pu}$. Like the heavier isotopes of $\mathrm{Pu}$, the production of americium is dependent on a sufficient concentration of precursors being present in fuel, and so their concentrations are low below $20 \mathrm{GWd} / \mathrm{tHM}$ burnups, though builds up more rapidly beyond this $\mathrm{BU}$. During reactor irradiation, the build-up of ${ }^{241} \mathrm{Am}$ is lower than that of ${ }^{243} \mathrm{Am}$ due to the capture cross section for conversion to ${ }^{242} \mathrm{Am}$ being an order of magnitude higher (720 b vs. 87.7 b).

${ }^{242} \mathrm{Am}$ is a short lived (16 h) isotope that decays via $\beta^{-}$decay to ${ }^{242} \mathrm{Cm}$, providing one of the two routes to that element. Around $20 \%$ of the time, however, neutron capture onto ${ }^{241} \mathrm{Am}$ produced ${ }^{242 \mathrm{~m}} \mathrm{Am}$, a longer-lived (141 y), and highly fissile metastable isotope, produced in sufficient quantities to be worthy of inclusion in our model. This decays via $y$-emission to ${ }^{242} \mathrm{Am}$. We modelled the three isotopes of Am with cubic functions with the zero burnup data point omitted to improve accuracy as per several of the Pu isotopes. This is illustrated in Figure 9. Zero intercepts were not forced with these isotopes as this improved the accuracy of the fit at higher burnups. Given the effective zero concentration at low burnups, values of 0 can effectively be entered at $10 \mathrm{GWd} / \mathrm{tHM}$ or below. Predicted concentration maxima for ${ }^{241} \mathrm{Am}$ and ${ }^{242} \mathrm{Am}$ are reached by burnups extrapolated to $70 \mathrm{GWd} / \mathrm{tHM}$ and decrease gradually beyond this point.

\subsection{5: Curium}

At burnups below $20 \mathrm{GWd} / \mathrm{tHM}$, the accumulation of curium isotopes in nuclear fuel is essentially negligible, only reaching appreciable amounts beyond $30 \mathrm{GWd} / \mathrm{tHM}$. For higher burnup fuels, however, these isotopes represent significant contributors to the short, medium, and long-term radiotoxicity generated by the fuel in storage scenarios and decay heat during recycling operations. With this in mind it is essential to have a comprehensive understanding of their behaviour, especially at high burnups. Curium is produced by two routes from americium, via the $\beta^{-}$decays of ${ }^{242} \mathrm{Am}$ and ${ }^{244} \mathrm{Am}$, themselves produced via neutron capture of ${ }^{241} \mathrm{Am}$ and ${ }^{243} \mathrm{Am}$. Although $\mathrm{Cm}$ isotopes with masses from 242 to 248 are generated, only those up to mass 246 are produced in any appreciable quantities. Of these isotopes, ${ }^{242} \mathrm{Cm}$ is short-lived, with a half-life of around half a year, ${ }^{243} \mathrm{Cm}$ and ${ }^{244} \mathrm{Cm}$ with half-lives of 29.1 and 18.1 y respectively, while ${ }^{245} \mathrm{Cm}$ and ${ }^{246} \mathrm{Cm}$ are longer-lived with halflives of thousands of years. All of the odd-mass isotopes are fissile, especially so in the case of ${ }^{243} \mathrm{Cm}$, which explains the low concentrations 
observed in fuel systems. Curium is the heaviest element to be isolated in appreciable amounts from power reactors, though high-flux research reactors can be used to produce the heavier elements berkelium, californium, and einsteinium. These values are included in the source data but beyond the scope of this work for inclusion. ${ }^{5}$ Curium isotopes also represent a significant source of spontaneous fission neutrons in high burnup fuel, primarily from ${ }^{242} \mathrm{Cm}$ and ${ }^{244} \mathrm{Cm}^{2}{ }^{2}$

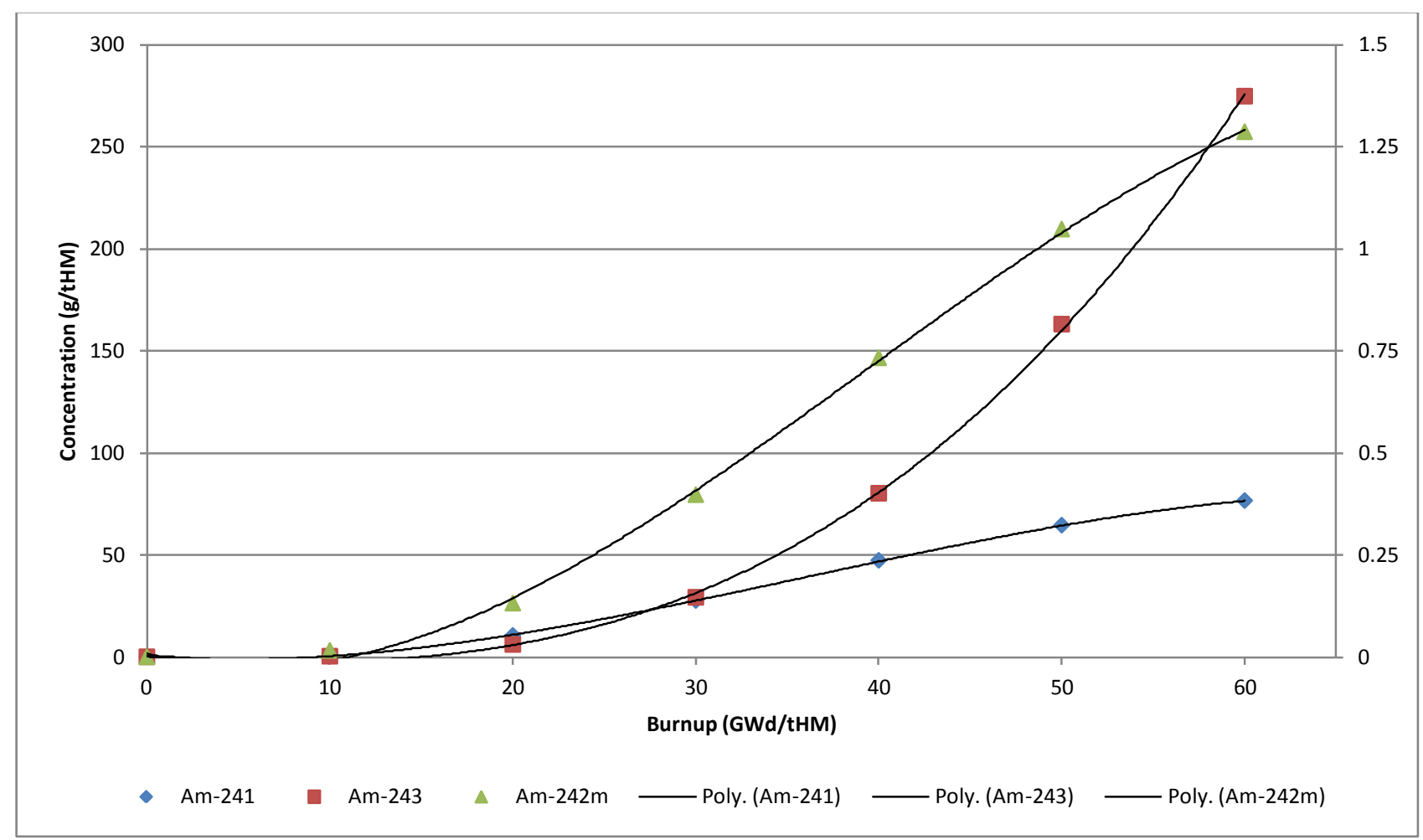

Figure 9: Experimental variations in concentration with burnup and polynomial fits for ${ }^{241} \mathrm{Am},{ }^{242 \mathrm{~m}} \mathrm{Am}$, and ${ }^{243} \mathrm{Am}$. NB: ${ }^{242 \mathrm{~m}} \mathrm{Am}$ concentrations are plotted on the secondary access.

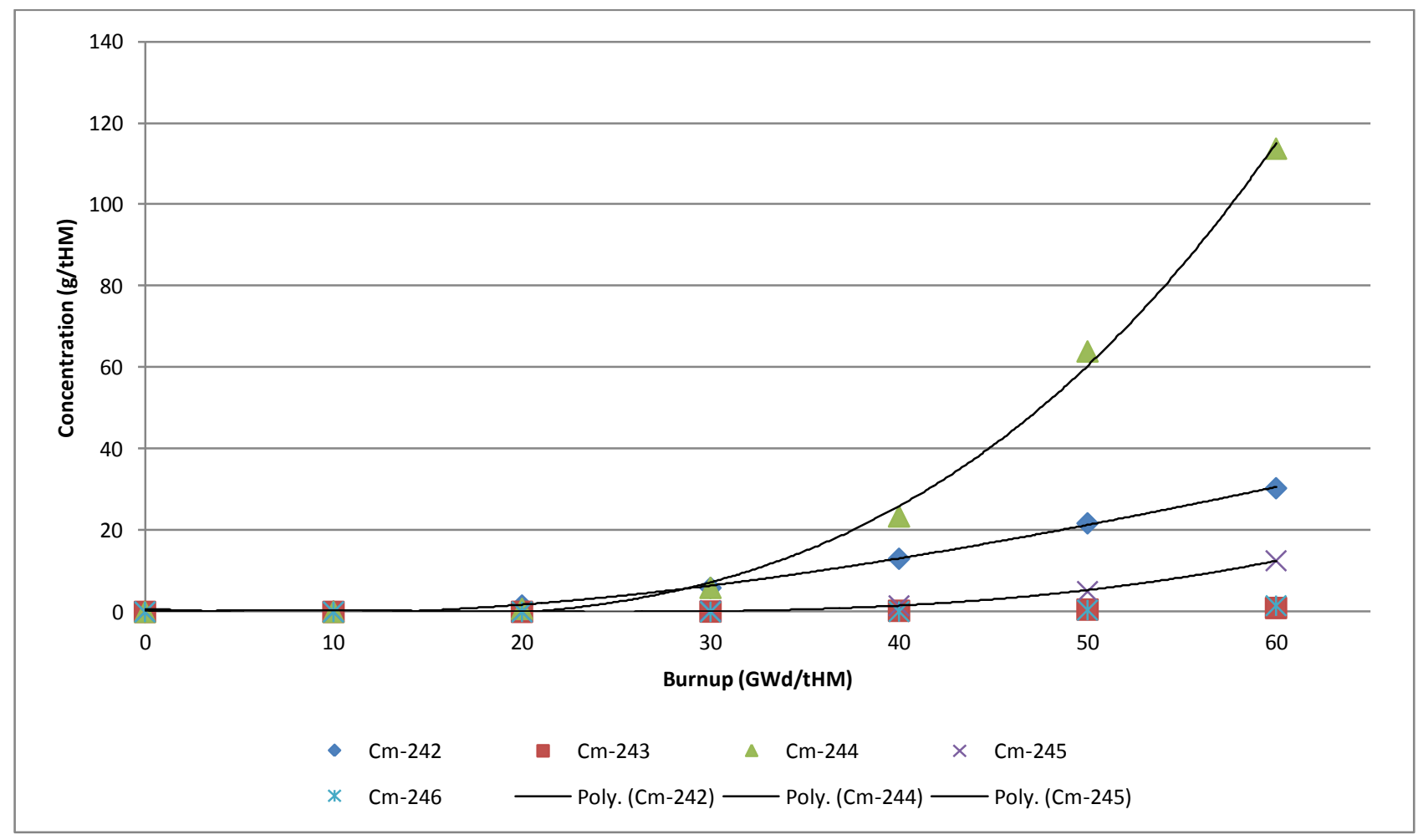

Figure 10: Experimental variations in concentration with burnup and polynomial fits for ${ }^{242} \mathrm{Cm}$ to ${ }^{246} \mathrm{Cm}$.

As per the heavier plutonium and americium isotopes, a sufficient quantity of precursors is required for the build-up of curium to occur, as observed in Figure 10. This means that none of these isotopes have reached their equilibrium concentrations, as demonstrated by the large increases in concentration once sufficient precursors are available at higher burnups. In order to achieve the best fit, for the higher mass $\mathrm{Cm}$ 
isotopes, the curve fitting omitted the lower burnup values, and zero-intercepts were not forced, though cubic fits provided adequate data fitting for the purposes of our model. All $\mathrm{Cm}$ isotopes were modelled with cubic functions. The fits for ${ }^{242} \mathrm{Cm}$ and ${ }^{243} \mathrm{Cm}$ omitted the zeroburnup data point for higher burnup accuracy, ${ }^{244} \mathrm{Cm}$ and ${ }^{245} \mathrm{Cm}$ omitted the zero and $10 \mathrm{GWd} / \mathrm{tHM}$ data points, while ${ }^{246} \mathrm{Cm}$ omitted the 0,10 , and $20 \mathrm{GWd} / \mathrm{tHM}$ data points, as outlined above. For ${ }^{242} \mathrm{Cm}$, this fit results in a concentration maximum around $95 \mathrm{GWd} / \mathrm{tHM}$ burnup, with the predicted concentrations for the rest of the isotopes increasing rapidly above this.

\subsection{6: Actinide Discharge Composition Fitting Parameters}

The collated polynomial curve-fitting parameters (Equation 2) derived in Figures $\mathbf{6}$ to $\mathbf{1 0}$ are presented in Table $\mathbf{4}$, alongside the \% errors recorded compared to the source data at 50 and $60 \mathrm{GWd} / \mathrm{tHM}$ burnups. It should be noted that in accordance with our primary aim for this work, concentration accuracy towards the higher burnups ( $\geq 50 \mathrm{GWd} / \mathrm{tHM}$ ) was far more important than at lower burnups, and as such, the aforementioned accommodations were made to allow for this.

Table 4: Discharge composition calculation parameters for polynomial fits.

\begin{tabular}{|c|c|c|c|c|c|c|c|c|}
\hline Nuclide & $a$ & b & c & d & e & $\mathbf{R}^{2}$ & $\begin{array}{l}\text { \%Err } \\
\text { (50 GWd) }\end{array}$ & $\begin{array}{l}\text { \%Err } \\
\text { (60 GWd) }\end{array}$ \\
\hline${ }^{34} U$ & - & - & 0.0144 & -5.0833 & 461.1 & 1.0000 & 0.2 & -0.2 \\
\hline${ }^{35} U$ & - & -0.03329 & 9.9397 & -1166.9 & 50000 & 0.9998 & 0.4 & -0.1 \\
\hline${ }^{36} U$ & - & 0.0069 & -2.231 & 216.13 & 308.2 & 0.9996 & 0.0 & 0.1 \\
\hline${ }^{238} \mathrm{U}$ & - & - & -2.7231 & -523.87 & 949230 & 1.0000 & 0.0 & 0.0 \\
\hline${ }^{237} \mathrm{~Np}$ & - & -0.0033 & 0.3695 & 4.9048 & - & 0.9959 & 0.6 & 0.2 \\
\hline${ }^{238} \mathrm{Pu}$ & - & - & 0.153 & -1.4663 & - & 0.9998 & -0.7 & 0.0 \\
\hline${ }^{239} \mathrm{Pu}$ & -0.0002617 & 0.07862 & -8.1852 & 368.813 & 344.567 & 1.0000 & 0.0 & 0.0 \\
\hline${ }^{240} \mathrm{Pu}$ & - & -0.0056 & 0.2564 & 59.247 & -221.11 & 0.9945 & 0.4 & 0.3 \\
\hline${ }^{241} \mathrm{Pu}$ & - & -0.0083 & 0.5546 & 33.937 & -243.13 & 0.9819 & 0.4 & -0.7 \\
\hline${ }^{242} \mathrm{Pu}$ & - & - & 0.3443 & -2.9472 & - & 0.9996 & -1.7 & 0.8 \\
\hline${ }^{241} \mathrm{Am}$ & - & -0.0007482 & 0.081251 & -0.96694 & 3.5295 & 0.9808 & 0.5 & -0.1 \\
\hline${ }^{242 m} \mathrm{Am}$ & - & -0.000013 & 0.0015074 & -0.024336 & 0.12067 & 0.9848 & 0.0 & -0.5 \\
\hline${ }^{243} \mathrm{Am}$ & - & 0.0006429 & 0.069672 & -2.1577 & 14.751 & 0.9949 & -0.9 & 0.2 \\
\hline${ }^{242} \mathrm{Cm}$ & - & -0.0001719 & 0.027567 & -0.58515 & 3.4299 & 0.9973 & -0.7 & 0.2 \\
\hline${ }^{243} \mathrm{Cm}$ & - & 0.0000016 & 0.0003261 & -0.010673 & 0.075816 & 0.9942 & -2.6 & 0.7 \\
\hline${ }^{244} \mathrm{Cm}$ & - & -0.0002561 & 0.11093 & -4.7171 & 53.113 & 0.9841 & -2.2 & 0.3 \\
\hline${ }^{245} \mathrm{Cm}$ & - & 0.0002563 & -0.018711 & 0.47724 & -4.0928 & 0.9436 & 0.3 & -0.1 \\
\hline${ }^{246} \mathrm{Cm}$ & - & 0.0000732 & -0.0074225 & 0.25732 & -3.0025 & 0.8968 & 1.0 & 0.5 \\
\hline
\end{tabular}

\section{4: Discharge Compositions}

Discharge compositions for unknown SNF HM compositions are calculated by summation of the individual isotopic concentrations ( $\mathrm{g} / \mathrm{tHM}$ ) at a given burnup. Elemental compositions were calculated by summation of all isotopes within an element (Table 1). Assuming an expected summed $\mathrm{HM}$ concentration value of $10^{6} \mathrm{~g} / \mathrm{tHM}$, we observe the predicted outputs of our model to be within $0.1 \%$ of the expected value for burnups of up to $75 \mathrm{GWd} / \mathrm{tHM}$, as outlined in Figure 11, which presents the variation in percentage difference between extrapolated outputs and the assumed HM concentration value with burnup. Refinements to the model would decrease the errors further, via inclusion of lowerconcentration nuclides and other approaches to the extrapolation of isotopic concentrations such as combined logarithmic and polynomial fitting of the concentration-burnup curves for each isotope. As our individual isotopic extrapolations are based on computationally-calculated values from a neutron transport code (ORIGEN2), ${ }^{5}$ any decays and transmutations that occur during reactor irradiation are accounted for.

\section{5: Storage Compositions and Decay Heat Calculations}

As the purpose of our model is to calculate the composition and decay heat of SNF in short-term storage (up to a decade) and in recycling scenarios, a simple model for the decay of short-medium lived FPs and actinides was required in order to determine the changes from our output discharge compositions at a given point in time. This would provide the desired compositional and radioactivity data with only two variable inputs in burnup and post-reactor cooling time (Figure 1).

For nuclides that decay via $\beta^{-}$emission, this was achieved via simple summation of the quantity of the parent isotope that had decayed at a given time after discharge as the mass of the atom does not change appreciably during this process (Equation 7). Although the vast majority of $\beta$-decaying nuclides modelled convert into others already present within the source data, ${ }^{151} \mathrm{Eu}$ and ${ }^{155} \mathrm{Gd}$ were added to the model to account for the decay of ${ }^{151} \mathrm{Sm}$, and ${ }^{155} \mathrm{Eu}$, respectively. Any isotopes with half-lives of tens of thousands of years or more can be considered stable for the purposes of our model, although they will provide essentially a constant source of decay heat. The modelled isotopes which undergo $\beta$ decay are presented in Table 5. These are the most significant FP contributors to SNF decay heat. ${ }^{2}$ 


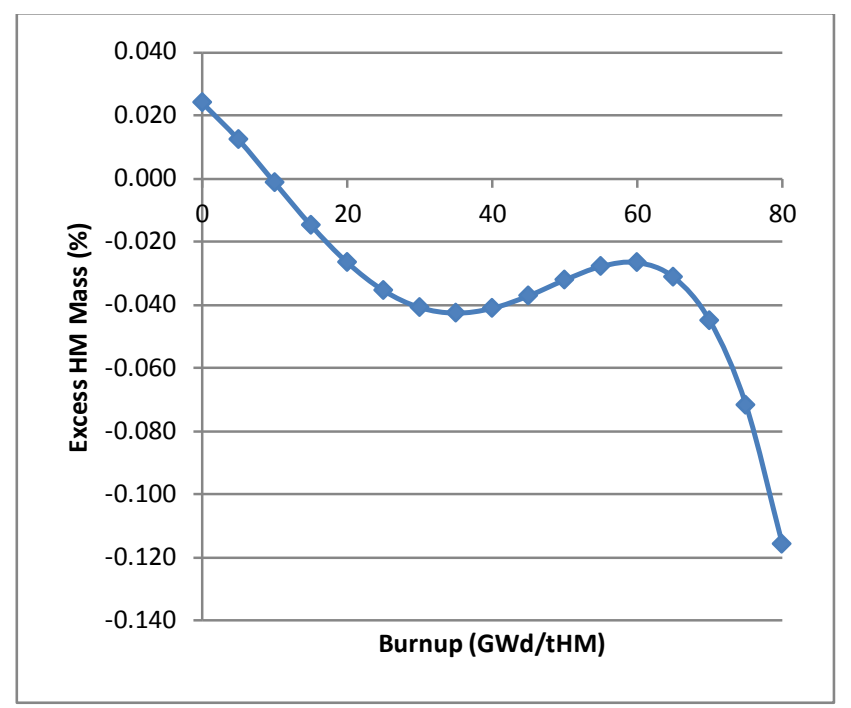

Figure 11: Variation in extrapolated total HM mass output of model with burnup at discharge, expressed as $\%$ excess over $10^{6} \mathrm{~g} / \mathrm{tHM}$.

For the actinide nuclides undergoing $\alpha$ decay (Table 6), a more complex approach is required given the mass lost to ${ }^{4}$ He production with each decay, and the interconnected decay and production of the actinide isotopes. As ${ }^{4} \mathrm{He}$ is one of the nuclides modelled (as a product of ternary fissions, primarily), the change in concentration of this over the storage time can be calculated. In order to achieve this, the molar amounts of each applicable nuclide decayed between discharge and a given storage time was calculated, ${ }^{1}$ the values summed, and added to the fission total for ${ }^{4} \mathrm{He}$ at discharge. The mass added for each daughter was similarly adjusted to account for atomic mass counting the alpha emission, with differential equations utilised to calculate the concentration of intermediate nuclides at a given cooling time.

Table 5: Modelled nuclides undergoing $\beta^{-}$decay with half-lives, calculated decay constants, decay energies $(\beta+\gamma)$, and gravimetric decay heats (DH). Nuclides marked with an asterisk $(*)$ include the decay energies of their short-lived intermediate daughters.

\begin{tabular}{ccccc}
\hline Isotope & $\mathbf{t}_{0.5}(\mathbf{y})$ & $\boldsymbol{\lambda}\left(\mathbf{y}^{-1}\right)$ & $\mathbf{Q}_{\boldsymbol{\beta}}(\mathrm{keV})$ & $\mathrm{DH}(\mathbf{W} / \mathrm{g})$ \\
\hline${ }^{85} \mathrm{Kr}$ & 10.74 & 0.0645 & 687.0 & 1.596 \\
${ }^{89} \mathrm{Sr}$ & 0.138 & 5.0235 & 1449.3 & 250.3 \\
${ }^{90} \mathrm{Sr}$ & 28.79 & 0.024 & $2824.4^{*}$ & 2.312 \\
${ }^{95} \mathrm{Zr}$ & 0.175 & 3.9511 & 1126.3 & 143.3 \\
${ }^{95} \mathrm{Nb}$ & 0.096 & 7.2304 & 925.6 & 215.5 \\
${ }^{103} \mathrm{Ru}$ & 0.108 & 6.4463 & 764.5 & 146.4 \\
${ }^{106} \mathrm{Ru}$ & 1.019 & 0.6805 & $3584.4^{*}$ & 70.39 \\
${ }^{110 m} \mathrm{Ag}$ & 0.684 & 1.0127 & $1505^{*}$ & 42.39 \\
${ }^{125} \mathrm{Sb}$ & 2.759 & 0.2513 & 766.7 & 4.715 \\
${ }^{134} \mathrm{Cs}$ & 2.065 & 0.3356 & 2058.7 & 15.78 \\
${ }^{137} \mathrm{Cs}$ & 30.08 & 0.0230 & 1175.6 & 0.605 \\
${ }^{141} \mathrm{Ce}$ & 0.089 & 7.7819 & 582.7 & 98.39 \\
${ }^{144} \mathrm{Ce}$ & 0.781 & 0.8880 & $3282.3 *$ & 61.93 \\
${ }^{147} \mathrm{Pm}$ & 2.623 & 0.2642 & 224.09 & 1.232 \\
${ }^{148 m} \mathrm{Pm}$ & 0.113 & 6.1274 & $3484.8^{*}$ & 441.4 \\
${ }^{151} \mathrm{Sm}$ & 90.00 & 0.0077 & 76.6 & 0.012 \\
${ }^{154} \mathrm{Eu}$ & 8.601 & 0.0806 & 1967.8 & 3.151 \\
${ }^{155} \mathrm{Eu}$ & 4.753 & 0.1458 & 251.8 & 0.725 \\
${ }^{241} \mathrm{Pu}$ & 14.33 & 0.0484 & 20.78 & 0.013 \\
${ }^{242 m} \mathrm{Am}$ & 141.0 & 0.0049 & $664.3^{*}$ & 0.041 \\
\hline
\end{tabular}

This method provides an approximation of actinide decay, although greater accuracy could be achieved by performing stepwise calculations at fine time steps, which is one prospect for further development of this model. The decay energies and overall decay heat produced by the actinides are generally lower than the FPs due to longer half-lives and lower concentrations, despite the higher energy of alpha decay. ${ }^{2}$ Decay heats were calculated by simple multiplication of the gravimetric decay heat (W/g, Equation 9) for each radioisotope with its concentration $(\mathrm{g} / \mathrm{tHM})$ at a given time point, which were then summed across all the isotopes to give an overall decay heat per tonne of HM. This approach, while simple, is flexible and adaptable, and readily applied to other parameters which will be discussed later. 
Table 6: Modelled nuclides undergoing $\alpha$ decay with half-lives, calculated decay constants, decay energies $(\alpha+\gamma)$, and gravimetric decay heats (DH).

\begin{tabular}{ccccc}
\hline Isotope & $\mathbf{t}_{0.5}(\mathbf{y})$ & $\boldsymbol{\lambda}\left(\mathbf{y}^{-1}\right)$ & $\mathbf{Q}_{\alpha}(\mathrm{keV})$ & $\mathrm{DH}(\mathrm{W} / \mathrm{g})$ \\
\hline${ }^{238} \mathrm{Pu}$ & 87.70 & 0.00790 & 5593.3 & 0.568 \\
${ }^{239} \mathrm{Pu}$ & 24110 & $2.87 \times 10^{-5}$ & 5244.5 & 0.002 \\
${ }^{240} \mathrm{Pu}$ & 6561 & 0.000106 & 5255.8 & 0.007 \\
${ }^{241} \mathrm{Am}$ & 432.6 & 0.001602 & 5637.8 & 0.115 \\
${ }^{243} \mathrm{Am}$ & 7364 & $9.41 \times 10^{-5}$ & 5439.1 & 0.006 \\
${ }^{242} \mathrm{Cm}$ & 0.446 & 1.55404 & 6215.6 & 122.2 \\
${ }^{243} \mathrm{Cm}$ & 29.1 & 0.023819 & 6168.8 & 1.850 \\
${ }^{244} \mathrm{Cm}$ & 28.1 & 0.024658 & 5901.6 & 1.825 \\
${ }^{245} \mathrm{Cm}$ & 8423 & $8.23 \times 10^{-5}$ & 5624.5 & 0.006 \\
${ }^{246} \mathrm{Cm}$ & 4706 & 0.000147 & 5475.1 & 0.010 \\
\hline
\end{tabular}

\section{6: Example Outputs}

Some example outputs from our model are presented in Figures 12 to 14, demonstrating the range of outputs presently available from our inhouse prototype developed using the methodology presented in this manuscript. Figure 12 highlights the elemental composition of a 65 GWd/tHM SF at discharge and after 1, 3, and 5 years post-reactor cooling, while Figures $\mathbf{1 3}$ and 14, present the variation in decay heats by nuclide of the FPs and actinides respectively with cooling time.

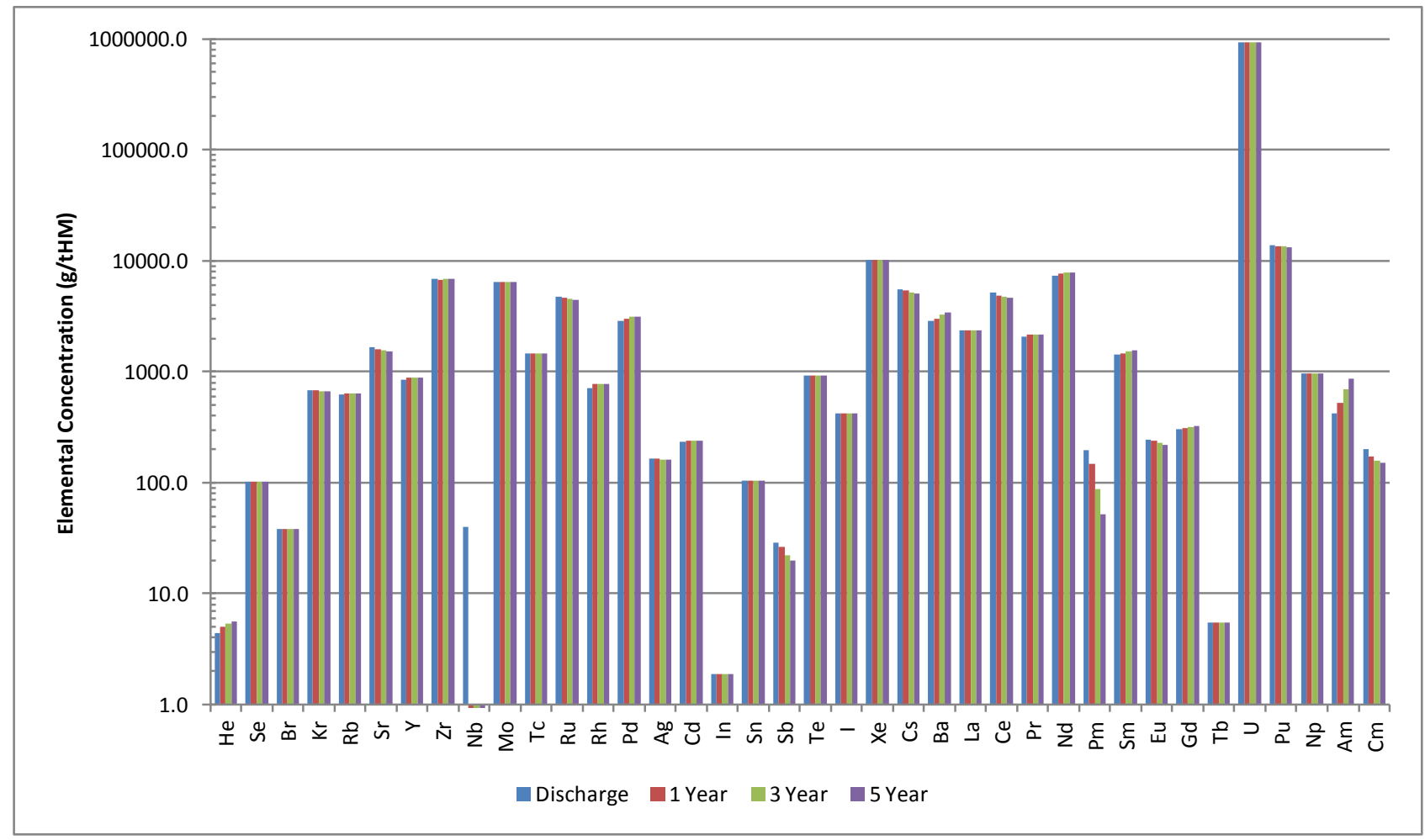

Figure 12: Variation in modelled SF elemental composition with cooling time, $5 \%$ initial enrichment, $65 \mathrm{GWd} / \mathrm{tHM}$ discharge burnup. NB y-axis is logarithmic scale.

The results presented in Figure $\mathbf{1 2}$ show the clear bimodal (double hump) distribution of fission products resulting from thermal fission of fissile actinide nuclei in PWR reactors. Note the $\mathrm{Nb}$ is an exception due to the short half-life of ${ }^{95} \mathrm{Nb}$, which rapidly decays to ${ }^{95} \mathrm{Mo}$. These results closely resembled those presented in the source data, ${ }^{5}$ albeit with the aforementioned simplifications accommodated in our model. Notable changes in concentrations modelled with cooling time are the increase in He from alpha decay, conversion of $\mathrm{Nb}$ to $\mathrm{Zr}$, $\mathrm{Sb}$ to $\mathrm{Te}$, Ce to $\mathrm{Ba}, \mathrm{Pm}$ to $\mathrm{Sm}$, and ${ }^{241} \mathrm{Pu}$ to ${ }^{241} \mathrm{Am}$, and decay of the short-lived ${ }^{242} \mathrm{Ce}$. From this, we can calculate appropriate dissolver liquor compositions for SF recycling scenarios to complement our ongoing research into separation processes. ${ }^{16-20}$

The results presented in Figures $\mathbf{1 3}$ and $\mathbf{1 4}$ demonstrate the logarithmic decay trend of the radioactive FPs, with the gradient of each line proportional to the rate of decay. As expected, many of the shorter-lived radioactive FPs produce the bulk of the decay heat at discharge, but these quickly decay over time so that longer-lived isotopes $\left({ }^{90} \mathrm{Sr}\right.$ and $\left.{ }^{137} \mathrm{Cs}\right)$ generate the bulk of the FP decay heat after 4 years of cooling. As several of the shortest lived (and most energetic) FPs are omitted by our model, the calculated decay heat at discharge (97.6 kW/tHM) will be 
an underestimation, although when the shortest lived of these nuclides (those with half-lives up to 10 days) have decayed, ${ }^{2}$ the accuracy of the model will increase.

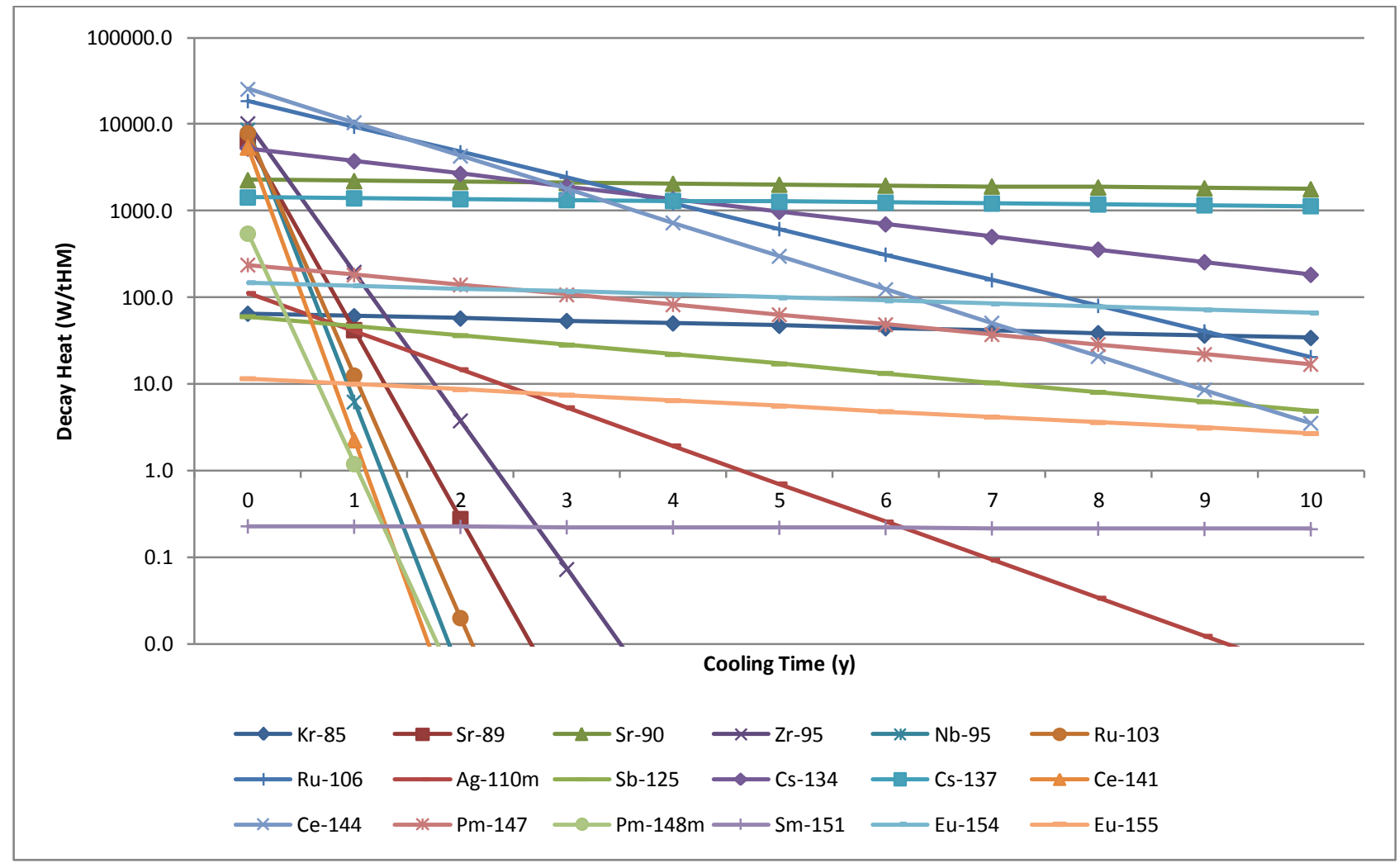

Figure 13: Variation in decay heat of fission products with cooling time. NB y-axis is logarithmic scale.

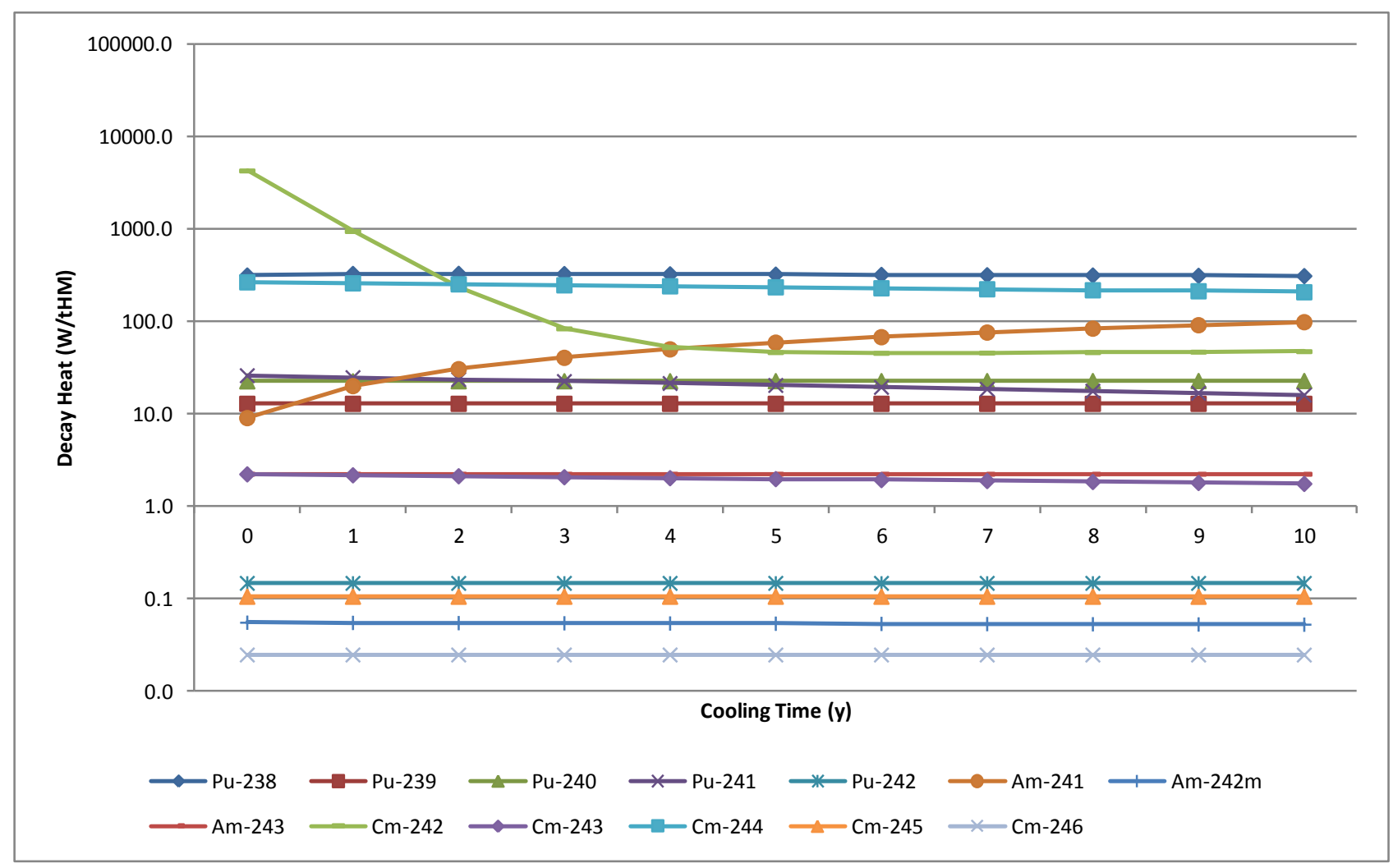

Figure 14: Variation in decay heat of (minor) actinides with cooling time. NB y-axis is logarithmic scale.

In all cases however, we account the total decay energy of each nuclide $\left(Q_{\alpha}\right.$ or $\left.Q_{\beta}\right)$ including gamma emission in addition to $\alpha$ and $\beta$ decay, so these values are likely an overestimation of total heat generated. For simplicity, short-lived intermediates such as ${ }^{90} \mathrm{Y}$ are counted with the parent nuclides $\left({ }^{90} \mathrm{Sr}\right.$ in this case). Then changes in the decay heat produced by the actinides are most apparent for but ${ }^{242} \mathrm{Cm}$ and ${ }^{241} \mathrm{Am}$, the former of which decays rapidly, and the latter of which is produced over time respectively from ${ }^{241} \mathrm{Pu}$. For the simulated durations of modelling 
SNF storage in this work (up to a decade), FPs dominate the production of decay heat, although the actinides are far more significant beyond this timescale into the many hundreds and even thousands of years. ${ }^{2}$ Such long-term behaviour could be readily incorporated into the model with additional calculations.

\section{4: Conclusions and Further Work}

In this work we have presented an overview of the methodology used to create a SNF composition and decay heat calculator based on a validated code, and discussed the capabilities and limits of the system. ${ }^{2,14,26}$ This is tailored to our own research needs for the study of model PWR systems in SNF recycling, but represents a small portion of what such an approach could deliver as the model can be tailored to researchers' own needs through the simplification or addition of components and calculations as required. For example, gravimetric neutron emission parameters (for criticality safety), ${ }^{2,12}$ gamma and other photon emission, isotopic activities, ${ }^{2}$ calculations of isotopic ratios ${ }^{5,14}$ etc. could be incorporated for additional functionality, providing the necessary source data is available in order to provide appropriate validation.

Further information such as burnup credits (fissile inventory and neutron poisons) are readily calculated using the same gravimetric approach used for decay heat outlined above. ${ }^{2,22}$ Burnup credits have already been partially implemented in our model, though these are not discussed here. In many respects, the model is effectively modular (as per some fuel simulation frameworks), ${ }^{1}$ requires very limited computing power, can be derived using non-proprietary software within the reach of all academic researchers, and a basic knowledge of statistics and physics first principles to achieve results with a good degree of accuracy. This serves to provide the information required for our research but is presently absent from the scientific record. This approach may not just be limited to SNF recycling, as modelling of tritium production ${ }^{27}$ or build-up of other radionuclides such as activation products ${ }^{28}$ in reactor coolant loops may be possible, alongside applications in other segments of the nuclear fuel cycle.

Although this work utilises only one set of SNF compositional data provided in the source, ${ }^{5}$ additional burnup levels ( 33 and $45 \mathrm{GWd} / \mathrm{tHM}$ ) with appropriate initial enrichments and equivalent MOX data are also available, with the equivalents duplicated for BWRs. These are alongside data for actinide decay products and counterion (oxide) activation products, ${ }^{5}$ which could all be drawn upon for additional model development, such as incorporating initial enrichment as an additional input parameter. This would allow for future reactor systems to be modelled, given the trend for increasing enrichments over time through to a current value of around $5 \%$ for advanced reactors. ${ }^{2,22}$ The model will continue to be refined over time and any developments in efficacy will be discussed in future publications alongside comparisons with outputs from established fuel performance codes. This model could also be tailored to accident tolerant or advanced technology fuels $(\text { ATFs })^{29,30,32,33}$ with alternative ceramics such as borides, ${ }^{30}$ carbides, $^{31}$ nitrides, ${ }^{29}$ and silicides, ${ }^{32}$ though this would require accommodation of fuel densities and neutronic behaviour. ${ }^{33}$ It may also be possible to model liquid fuel systems as found in molten salt reactors with further adaptions to the model.

It should be noted that due to the sensitive nature of this field of work, our full model is not included with this publication, although the source data and related isotopic information is freely available. ${ }^{5}$ We envisage this approach as a complementary method to the established neutron performance codes in use in the nuclear field, more suited to those researchers with a strong experimental focus rather than computationalor modelling-focused scientists with the requisite programming experience and access to the necessary resources.

\section{5: References:}

1. K. D. Huff, M. J. Gidden, R. W. Carlsen, R. R. Flanagan, M. B. McGarry, A. C. Opotowsky, E. A. Schneider, A. M. Scopatz, and P. P. H. Wilson, Adv. Eng. Softw., 2016, 94, 46-59. https://doi.org/10.1016/j.advengsoft.2016.01.014

2. J. Hu, I. C. Gauld, J. L. Paterson, S. M. Bowman, and M. Aissa, NUREG/CR-7227, ORNL/TM-2015/619, US Commercial Spent Nuclear Fuel Assembly Characteristics: 1968-2013, 2016, ONRC, DC, USA.

3. A. Figueroa and M. Gottsche, arXiv, 2020, preprint. https://arxiv.org/abs/2006.12921

4. R. W. Mills, B. M. Slingsby, J. Coleman, R. Collins, G. Holt, C. Metelko, and Y. Schnellback, Nucl. Eng. Tech., 2020, 52, 21302137. https://doi.org/10.1016/i.net.2020.03.004

5. Y. Andi and H. Takano, JAERI Research 99-004, Estimation of LWR Spent Fuel Composition, 1999, Japanese Atomic Energy Research Institute, Tokai, Japan (mostly in Japanese).

6. IAEA-TECDOC-1587, Spent Fuel Reprocessing Options, 2008, Nuclear Fuel Cycle and Materials Section, IAEA, Vienna, Austria.

7. New Systems to Curb Waste at Source?, 2005-2006, CLEFS CEA, 53, CEA, France.

8. Nuclear Waste Management and Processing: Between Legacy and Anticipation, 2005-2006, CLEFS CEA, 53, CEA, France.
9. Spent Fuel Reprocessing: A Fully Mastered Pathway, 2005-2006, CLEFS CEA, 53, CEA, France.

10. M. Ternovykh, G. Tikhorimov, I. Saldikov, and A. Gerasimov, EPJ Web Conf., 2017, 153, 07035. https://doi.org/10.1051/epjconf/201715307035

11. W. Culbreth, E. Bakker, and J. Viggato, The Fission Properties of Curium Separated from Spent Nuclear Fuel, 2002, University of Nevada, Las Vegas, USA, 1-51.

12. A. Sasahara, T. Matsumura, G. Nicolaou, and Y. Kiyanagi, J. Nucl. Sci. Tech., 2008, 45, 4, 313-327. https://doi.org/10.1080/188118.2008.9711440

13. C. E. Sanders, I. C. Gauld, and R. Y. Lee, Isotopic Analysis of HighBurnup PWR Spent Fuel Samples from the Takahama-3 Reactor, NUREG/CR-6798, ORNL/TM-2001/259, 2003, ONRC, DC, USA.

14. M. W. Francis, C. F. Weber, M. T. Pigni, and I. C. Gauld, ORNL/TM2014/464, Reactor Fuel Isotopics and Code Validation for Nuclear Applications, 2014, Oak Ridge National Lab, TN, USA.

15. G. Ilas, I. C. Gauld, B. D. Murphy, and M. Aissa, NUREG/CR-6969, ORNL/TM-2008/072, Analysis of Experimental Data for High Burnup PWR Spent Fuel Isotopic Validate - ARIANE and REBUS Programs (UO $\mathrm{O}_{2}$ Fuel), 2010, ONRC, DC, USA.

16. G. Bond, H. Eccles, P. C. Kavi, A. F. Holdsworth, D. Rowbotham, and R. Mao, J. Chromatog. Sep. Tech., 2019, 10, 417. https://doi.org/10.4172/2157-7064.100041 
17. A. F. Holdsworth, H. Eccles, D. Rowbotham, G. Bond, P. C. Kavi, and R. Edge, Separations, 2019, 6, 2, 23. https://doi.org/10.3390/separations6020023

18. A. F. Holdsworth, H. Eccles, D. Rowbotham, A. Brookfield, D. Collison, G. Bond, P. C. Kavi, and R. Edge, Clean. Tech., 2019, 1, 1, 294-310. https://doi.org/10.3390/cleantechnol1010020

19. Reprocessing of Spent Nuclear Fuel, R. Taylor (Ed.), 2015, Woodhead, Cambridge, UK. https://doi.org/10.1016/C2013-0$\underline{16483-5}$

20. A. C. Edwards, P. Mocilac, A. Geist, L. M. Harwood, C. A. Sharrad, N. A. Burton, R. C. Whitehead, and M. A. Denecke, Chem. Commun., 2017, 53, 5001-5004. https://doi.org/10.1039/C7CC01855J

21. O. W. Hermann, C. V. Parks, and J. P. Renier, NUREG/CR-5625, ORNL-6698, Technical Support for a Proposed Decay Heat Guide Using SAS2H/ORIGEN-S Data, 1994, Oak Ridge National Lab, TN, USA.

22. D.-K. Cho, S.-K. Yoon, H.-J. Choi, J. Choi, and W. I. Ko, J. Korean Radioact. Waste Soc., 2008, 6, 3, 225-232.

23. https://nds.iaea.org/relnsd/vcharthtml/VChartHTML.html (Accessed Sept. 2020)

24. K.-H. Lee, H.-K. Park, and Y. M. Shin, J. Nucl Med Tech., 2016, 20, 2, 69-74.
25. B. Pellaud, C. R. Physique, 2002, 3, 1067-1079. https://doi.org/10.1016/S1631-0705(02)01364-6

26. C. V. Parks, M. D. DeHart, J. C. Wagner, and C. W. Nilsen, NUREG/CR-6665, ORNL/TM-1999/303, 2000, ONRC, DC, USA

27. M. Atlas, N. Brickner, W. Chen, and D. Tsai, Tritium Management Approach for FHRs Using Supercritical Steam, Open-Air Brayton, and Closed Gas Brayton Power Cycles, Report UCBTH-12-006, 2012, UC Berkeley, CA, USA.

28. K. A. Burrill, Nucl. Tech., 1977, 36, 1, 85-92. https://doi.org/10.13182/NT77-A31962

29. W. Li and K. Shirvan, J. Nucl. Mater., 2020, 542, 152479. https://doi.org/10.1016/j.jnucmat.2020.152479

30. J. Turner, F. Martini, J. Buckley, G. Phillips, S. C. Middleburgh, and T. J. Abram, J. Nucl. Mater., 2020, 540, 152388. https://doi.org/10.1016/j.jnucmat.2020.152388

31. Y. Arai, T. Iwai, and T. Ohmichi, J. Nucl. Mater., 1987, 151, 1, 6371. https://doi.org/10.1016/0022-3115(87)90056-0

32. J. M. Harp, P. A. Lessing, and R. E. Hoggan, J. Nucl. Mater., 2015, 466, 728-738. https://doi.org/10.1016/i.jnucmat.2015.06.027

33. K. A. Terrani, J. Nucl. Mater., 2018, 501, 13-30. https://doi.org/10.1016/j.jnucmat.2017.12.043

34. M. S. Greenwood and B. Betzler, Nucl. Sci. Eng., 2019, 193, 4, 417430. https://doi.org/10.1080/00295639.2018.1531619

\section{6: Acknowledgements and Notes:}

We wish to thank Mr A. H. H. Peart (Univ. Lancaster) for his valued inputs and discussions. This work was conducted as part of the UK EPSRC ATLANTIC (Accident Tolerant Fuels in Recycling) grant (EP/S011925/1). The authors declare no conflicts of interest. 